\title{
Network Pharmacology-Based Investigation of the System-Level Molecular Mechanisms of the Hematopoietic Activity of Samul-Tang, a Traditional Korean Herbal Formula
}

\author{
Ho-Sung Lee, ${ }^{1,2}$ In-Hee Lee, ${ }^{1}$ Sang-In Park, ${ }^{3}$ and Dae-Yeon Lee $\mathbb{i D}^{1,2}$ \\ ${ }^{1}$ The Fore, 87 Ogeum-ro, Songpa-gu, Seoul 05542, Republic of Korea \\ ${ }^{2}$ Forest Hospital, 129 Ogeum-ro, Songpa-gu, Seoul 05549, Republic of Korea \\ ${ }^{3}$ Forestheal Hospital, 173 Ogeum-ro, Songpa-gu, Seoul 05641, Republic of Korea
}

Correspondence should be addressed to Dae-Yeon Lee; foresthrnd@gmail.com

Received 15 October 2019; Accepted 3 January 2020; Published 13 February 2020

Academic Editor: Khalid Rahman

Copyright (C) 2020 Ho-Sung Lee et al. This is an open access article distributed under the Creative Commons Attribution License, which permits unrestricted use, distribution, and reproduction in any medium, provided the original work is properly cited.

Hematopoiesis is a dynamic process of the continuous production of diverse blood cell types to meet the body's physiological demands and involves complex regulation of multiple cellular mechanisms in hematopoietic stem cells, including proliferation, self-renewal, differentiation, and apoptosis. Disruption of the hematopoietic system is known to cause various hematological disorders such as myelosuppression. There is growing evidence on the beneficial effects of herbal medicines on hematopoiesis; however, their mechanism of action remains unclear. In this study, we conducted a network pharmacological-based investigation of the system-level mechanisms underlying the hematopoietic activity of Samul-tang, which is an herbal formula consisting of four herbal medicines, including Angelicae Gigantis Radix, Rehmanniae Radix Preparata, Paeoniae Radix Alba, and Cnidii Rhizoma. In silico analysis of the absorption-distribution-metabolism-excretion model identified 16 active phytochemical compounds contained in Samul-tang that may target 158 genes/proteins associated with myelosuppression to exert pharmacological effects. Functional enrichment analysis suggested that the targets of Samul-tang were significantly enriched in multiple pathways closely related to the hematopoiesis and myelosuppression development, including the PI3K-Akt, MAPK, IL-17, TNF, FoxO, HIF-1, NFkappa B, and p53 signaling pathways. Our study provides novel evidence regarding the system-level mechanisms underlying the hematopoiesis-promoting effect of herbal medicines for hematological disorder treatment.

\section{Introduction}

Hematopoiesis refers to the process of development of immature precursor cells into various mature and functional blood cells, which initiates from the self-renewing multipotent hematopoietic stem cells (HSCs) [1,2]. This biological process involves accurate coordination of cellular proliferation, differentiation, and survival of progenitor cells to maintain hematopoietic homeostasis modulated by the activity of various cytokines, growth factors, and key regulatory factors, as well as the complex interactions between hematopoietic cells, tissues, and organs $[1,2]$. However, hematopoietic homeostasis disruption caused by various reasons, including anticancer therapies (e.g., chemotherapy and radiotherapy), myeloid malignancies, nutritional deficiencies, or viral infection, may lead to the development of hematological disorders (HDs) such as myelosuppression [3-5]. Myelosuppression is a pathophysiological condition characterized by reduced bone marrow ability to produce sufficient amounts of blood cells (e.g., erythrocytes, leukocytes, and thrombocytes), which results in immunodeficiency, anemia, leukocytopenia, neutropenia, and thrombocytopenia. [3-5]. Symptoms of myelosuppression include fatigue, headache, fever, infection, bruising, shortness of breath, excessive bleeding, pain, and diarrhea, which might affect the quality of life and could be life-threatening if not effectively managed [4-9]. The current pharmacological strategies for treating myelosuppression involve the administration of erythropoietin (EPO), granulocyte colonystimulating factor (G-CSF), and granulocyte-macrophage 
colony-stimulating factor (GM-CSF) [10-12]; however, they have been reported to cause unfavorable side effects such as bone and muscle pains, fever, flushing, and nausea $[13,14]$. This indicates the need to develop therapies for effective HD amelioration with improved safety. Herbal medicines, which are characterized by multicomponents, multitarget, and multipathway pharmacological mechanisms [15-17], have attracted considerable attention and are recognized as effective therapeutic agents for the myelosuppression alleviation; further, they have fewer side effects than conventional therapies [18-24]. There is growing evidence on the beneficial effects of various herbal medicines in terms of promotion and enhancement of hematopoiesis in vitro and in vivo [25-33].

Samul-tang (Si-wu-tang; SMT) is an herbal formula comprising four herbal medicines, including Angelicae Gigantis Radix (Angelica gigas; AGR), Rehmanniae Radix Preparata (Rehmannia glutinosa; RRP), Paeoniae Radix Alba (Paeonia lactiflora; PRA), and Cnidii Rhizoma (Cnidium officinale; CR) [34-36]. It is commonly used to treat various HDs and related symptoms such as anemia [37], dysmenorrhea [38-40], chemotherapy-induced myelosuppression [41, 42], and menstrual disorders [43]. Previous studies have reported that the hematopoietic effects of SMT partly involve the modulation of cellular processes in bone marrow cells, HSCs, and blood cells (e.g., erythrocytes, leukocytes, and thrombocytes), as well as the activities of key hematopoietic factors (e.g., EPO, G-CSF, interleukins (ILs), and interferon(IFN-) $\gamma$ ) [42, 44-46]. However, the system-level molecular therapeutic mechanisms of SMT are yet to be fully elucidated.

Network pharmacology is an interdisciplinary science that aims to uncover the pathophysiological mechanisms underlying various diseases and their treatment strategies at a system-level by integrating biomedicine, pharmacology, systems biology, network biology, computational science, and other related scientific fields $[16,47,48]$. This interdisciplinary approach has been shown to be useful for discovering active compounds contained in herbal drugs and their corresponding potential targets, and investigating the therapeutic mechanisms that involve complex interactions between multiple compounds and targets, which may facilitate the exploration of the pharmacological properties of herbal medicines [47, 48]. In this study, we conducted a network pharmacology-based investigation of the systemlevel molecular mechanism underlying the hematopoietic activity of SMT.

\section{Materials and Methods}

2.1. Investigation of Chemical Compounds Contained in SMT. We retrieved the chemical compounds present in the four herbal medicines that constitute SMT (i.e., AGR, RRP, PRA, and CR) from traditional Chinese medicine (TCM)-related databases, including the Traditional Chinese Medicine Systems Pharmacology (TCMSP) database, Traditional Chinese Medicine Integrated Database (TCMID), and Herb Ingredients' Targets (HIT) database [49-52]. Regarding AGR, we first explored the biochemical constituents of
Angelicae Sinensis Radix, a commonly used herbal medicine in China that belongs to the Angelicae species, using the aforementioned TCM-related databases, and combined those with the reported major compounds of AGR such as marmesin, lomatin, and decursin [53-55]. Chemical compounds not contained in AGR, including isoeugenol, stigmasterol, and 4-octanone, were excluded from the integrated data based on previous studies [53-55].

2.2. Exploration of Active Compounds of SMT. To investigate the potential bioactive chemical compounds in SMT, we explored the absorption, distribution, metabolism, and excretion (ADME) properties of each individual phytochemical compound present in the four herbal constituents of SMT. In this study, we assessed the three commonly used ADME-related parameters (oral bioavailability (OB), Caco-2 permeability, and drug-likeness (DL)) for each compound [52]. OB indicates the fraction of an ingested dose of a given drug that crosses the gastrointestinal epithelium, enters the systemic circulation, and becomes available for distribution to internal tissues and organs $[52,56]$. Caco-2 permeability is used to assess the absorption capacity of drug molecules and chemical compounds in the intestines based on their passage rate through the Caco-2 human colon epithelial cancer cell line [52, 57-59]. Notably, Caco-2 cells are commonly used as a model for evaluating the intestinal absorption capacity of biochemical compounds since they have morphologic features similar to those of human intestinal epithelial cells [57-59]. Generally, compounds with Caco-2 permeability $<-0.4$ are regarded as impermeable in the small intestinal epithelium $[60,61]$. DL is a key qualitative criterion used in drug design to determine candidate chemical components that may be used as drugs based on their structural and pharmacokinetic characteristics $[52,62]$. Based on previous studies, we regarded chemical compounds with $\mathrm{OB} \geq 30 \%$, Caco- 2 permeability $\geq-0.4$, and $\mathrm{DL} \geq 0.18$ as pharmacologically active $[52,63,64]$.

\subsection{Investigation of the Targets of Active Compounds in SMT.} We investigated human target genes/proteins that interact with active phytochemical compounds in SMT using the Search Tool for Interactions of Chemicals (STITCH) 5 [65], Similarity Ensemble Approach (SEA) [66], SwissTargetPrediction [67, 68], and PharmMapper [69]. Computational modeling methods, including systematic drug targeting tool (SysDt) [70] and weighted ensemble similarity (WES) algorithm [71], were also employed for target identification as descried previously [72-78]. Subsequently, we confirmed detailed information regarding the targets, including their scientific name, relevant gene/protein ID, and organism, and further standardized the targets using Uniprot [79]. The myelosuppression-associated human genes/proteins were surveyed using diverse databases, including Online Mendelian Inheritance in Man (OMIM) [80], Therapeutic Target Database (TTD) [81], GeneCards [82], DrugBank [83], Pharmacogenomics Knowledge for Personalized Medicine (PharmGKB) [84], DisGeNET [85], Human Genome Epidemiology (HuGE) Navigator [86], and 
The Comparative Toxicogenomics Database (CTD) [87] by using search terms for various myelosuppression-related disorders, including "anemia," "leukopenia," "neutropenia," "thrombocytopenia," "lymphopenia," "granulocytopenia," and "agranulocytosis, with the search species limited to "Homo sapiens".

2.4. Construction of SMT-Associated Networks. The herbcompound ( $\mathrm{H}-\mathrm{C})$ and compound-target (C-T) networks were constructed by linking the herbal medicines with their active compounds and the active compounds with their corresponding targets, respectively. The target-pathway (T-P) network was built by linking the targets with their associated signaling pathways. All networks were visualized using Cytoscape software (version 3.7.1) [88]. The target location network was generated based on the analysis of gene expression data of various hematopoietic tissues and organs obtained from The Human Protein Atlas [89] and BioGPS databases [90]; this network was generated by linking the target to the corresponding tissues and organs where it was analyzed to be specifically expressed using previously described procedures [91-98]. The protein-protein interaction (PPI) network was constructed using the STRING database (version 11.0) [99] and interactions with highest confidence scores $(\geq 0.9)$ were selected for further analysis. In the network, nodes represent the herbal medicines, active phytochemical compounds, targets, or signaling pathways while edges represent the interactions between the nodes [100]. The degree of a node refers to the number of connections it has to other nodes in the network [100].

2.5. Functional Enrichment Analysis. Functional enrichment analysis of SMT-targeted genes or proteins was conducted using g:Profiler [101], which is an efficient web server-based tool for the functional profiling of a given list of genes or proteins, and Kyoto Encyclopedia of Genes and Genomes (KEGG) database [102].

\section{Results}

The pharmacological mechanisms of SMT were investigated based on the network pharmacology perspective as follows (Figure 1). First, we extensively surveyed the chemical compounds contained in the four herbal medicines that comprise SMT using various TCM-related databases (Figure 1). Next, we assessed ADME parameters, such as OB, Caco-2 cell permeability, and DL, for each individual chemical compound to identify potential bioactive compounds (Figure 1). Subsequently, we determined potential targets of the active chemical compounds by exploring the protein-chemical interactions using relevant databases and conducted functional enrichment analysis of the targets (Figure 1). Furthermore, we merged comprehensive information regarding SMT into the $\mathrm{H}-\mathrm{C}, \mathrm{C}-\mathrm{T}, \mathrm{T}-\mathrm{P}$, and target location networks and investigated its pharmacological properties based on network pharmacology analysis (Figure 1).
3.1. Chemical Compounds of SMT. We investigated the chemical compounds contained in the four herbal medicines (i.e., AGR, RRP, PRA, and CR) that comprise SMT from a number of TCM-related databases (e.g., TCMSP, TCMID, and HIT). Consequently, we obtained 126, 76, 85, and 189 compounds for AGR, RRP, PRA, and CR, respectively, and identified 440 compounds after duplicate removal (Supplementary Table S1).

3.2. Investigation of the Active Phytochemical Compounds of SMT. In silico ADME models have been widely used to investigate active phytochemical compounds that may possess therapeutic properties $[52,62]$. To determine the potential active compounds of SMT, we evaluated the ADME parameters (i.e., OB, Caco-2 permeability, and DL) of each individual compound contained in the four herbal medicines comprising the herbal formula. As previously described, we considered compounds with $\mathrm{OB} \geq 30 \%$, Caco2 permeability $\geq-0.4$, and $\mathrm{DL} \geq 0.18$ as pharmacologically active $[63,64]$. Moreover, we considered some compounds that did not meet the aforementioned criteria as active components due to their high amount and pharmacological activity. Collectively, 18 active compounds were retrieved for SMT (Supplementary Table S2).

3.3. Identification of the Targets of Active Phytochemical Compounds in SMT. To identify the potential therapeutic targets of SMT, we employed an in silico approach to assess the biological interactions between the active phytochemical compounds and human genes/proteins using STITCH 5 [65], SEA [66], SwissTargetPrediction [67, 68], and PharmMapper [69]. Computational modeling methods such as SysDt [70] and WES algorithm [71] were also employed for target identification as descried previously [72-78]. Hence, a total of 230 targets were obtained for the 16 active phytochemical compounds in SMT (Supplementary Table S3). Note that no potential pharmacological targets were identified for the case of two active compounds (i.e., 11alpha,12alpha-epoxy-3beta-23-dihydroxy-30-norolean-20en-28,12beta-olide and Paeoniflorin_qt).

3.4. Network-Based Analysis of the Pharmacological Mechanisms of SMT. To understand the "multicomponents, multitarget, and multipathway" pharmacological mechanisms of SMT, we constructed an herb-compound-target (H-C-T) network by linking the herbal medicines with the active phytochemical compounds and the active compounds with their potential targets (Figure 2). The H-C-T network for SMT was composed of 250 nodes and 393 edges, including the 4 herbal medicines, 16 active compounds, and 230 targets (Figure 2). Furthermore, for network-based investigation of the system-level therapeutic properties of SMT, we built a C-T network comprised of 173 nodes and 274 edges by linking the active compounds with their myelosuppression-related targets (Figure 3 and Supplementary Table S3). Of note, none of the targets associated with myelosuppression showed potential interactions with 


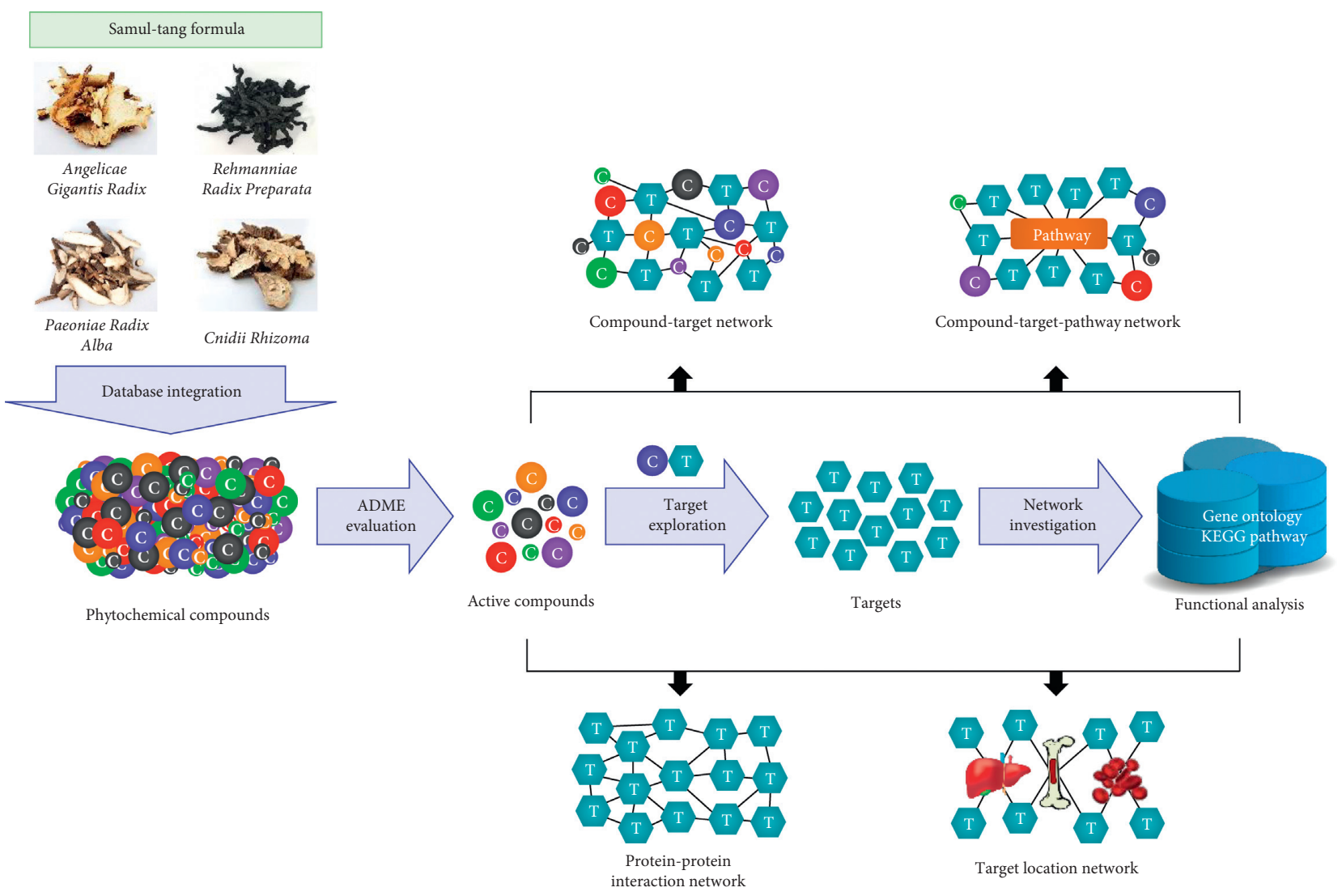

Figure 1: A schematic diagram representing the workflow of the network pharmacology-based investigation of the pharmacological mechanisms of SMT.

the active compound Senkyunone. The active phytochemical compounds kaempferol (degree $=73)$, stigmasterol $($ degree $=34), \beta$-sitosterol $($ degree $=31)$, and $(+)$-catechin (degree $=25)$ had the largest number of connections with the myelosuppression-related targets (Figure 3), which indicated them as the potential primary active compounds responsible for the hematopoietic activity of SMT. Moreover, 53 targets had two or more interactions with the active phytochemical compounds (Figure 3), which demonstrates the multicompound, multitarget pharmacological characteristic of herbal medicines, including SMT.

To investigate the underlying relationship between the targets interacting with the active ingredients in SMT, we built a PPI network comprised of 123 nodes and 333 edges for the myelosuppression-associated SMT targets (Figure 4). The centralization and heterogeneity of the PPI network were 0.411 and 2.249, respectively, which suggested that the network may contain hubs, nodes with a large number of interactions $[63,100,103-105]$. Here, a node was determined to be a hub if its degree is greater than or equal to twice the average node degree of the network $[106,107]$. Notably, hub nodes have been reported to function as important regulators in a variety of biological processes [108, 109]. Among the myelosuppression-related targets of SMT, AKT1 (degree $=21)$, TNF $($ degree $=21)$, MAPK14 $($ degree $=19)$, RELA $($ degree $=17)$, JUN (degree $=16), \quad$ HSP90AA1 $($ degree $=16), \quad$ RXRA $($ degree $=16)$, CTNNB1 $($ degree $=15)$, NR3C1 $($ degree $=15)$,
ESR1 $($ degree $=15)$, MAPK8 $($ degree $=14)$, NCOA2 $($ degree $=$ 13), AR (degree $=13)$, EGFR (degree $=13)$, CXCL8 (degree = 12), CYP3A4 (degree $=11)$, CYP1A1 (degree $=11)$, and PRKACA (degree $=11$ ) were found to be hub nodes, suggesting that they may play key roles in the hematopoietic activities of SMT (Figure 4). Previous studies have reported a close association between these targets and hematopoiesis or myelosuppression development. For instance, AKT1, TNF, RELA, $\beta$-catenin (encoded by CTNNB1), ESR1, and AR have been reported to serve as important regulators that coordinate HSC function [110-115]. The p38 (encoded by the MAPK14) cascade controls the quiescence and expansion of HSCs, which are crucial processes for maintaining hematopoietic homeostasis [116-122]. The p38, JNK1 (encoded by MAPK8), and c-JUN (encoded by JUN) are essential for erythropoiesis regulation, which is the biological process whereby hematopoietic tissues in the bone marrow produce erythrocytes by modulating proliferation, apoptosis, and differentiation of erythroid cells [123-126]. EGFR promotes HSC regeneration and function after radiotherapy-induced myelosuppressive injury [127]. The cytokine CXCL8 (also known as IL-8) has been reported to stimulate HSC mobilization to exert a radioprotective effect [128].

To understand the therapeutic effects of SMT at the tissue- and organ-level, we generated a target location network based on the gene expression data for individual myelosuppression-associated SMT targets across various 


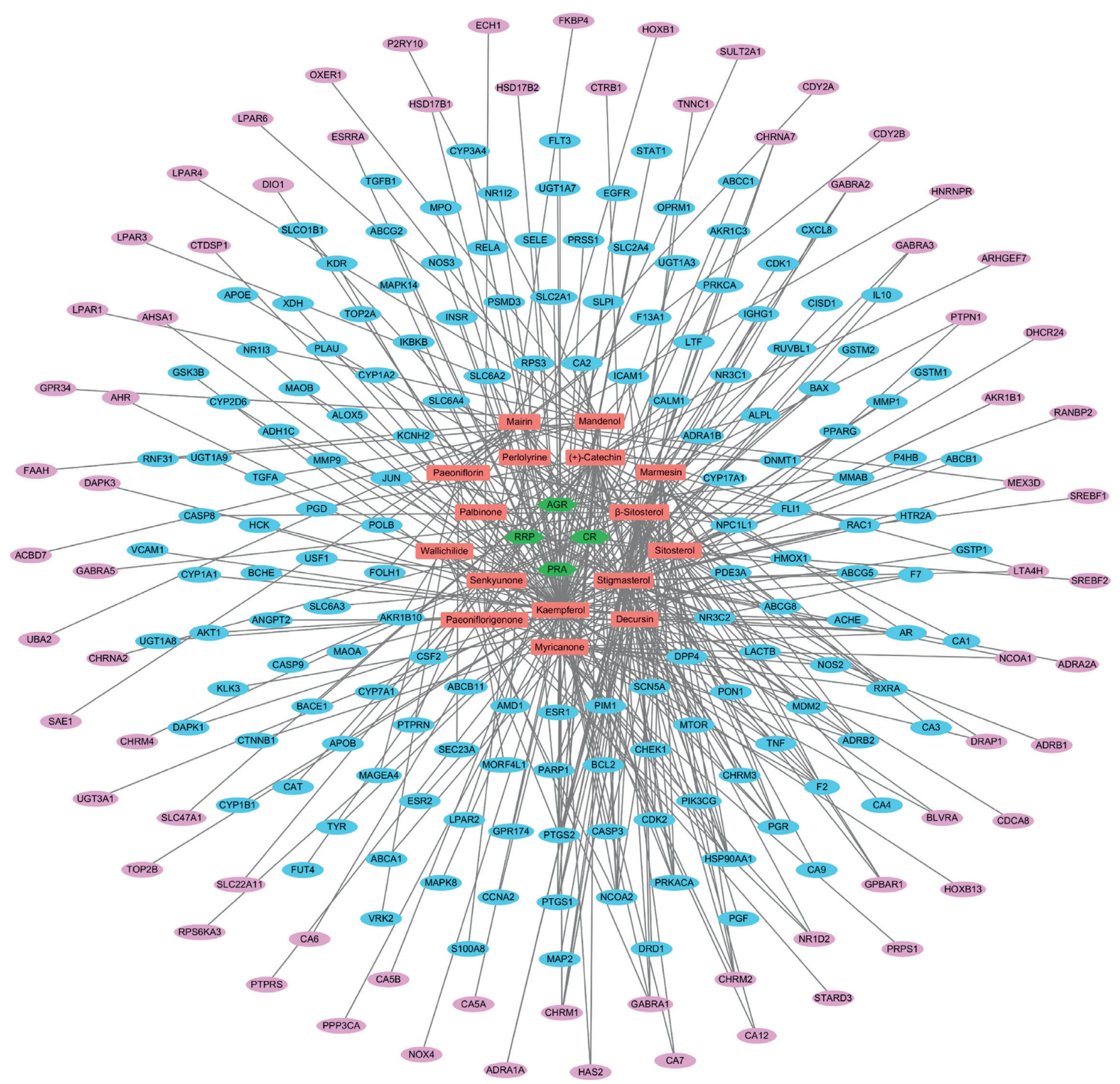

FIGURE 2: The herb-compound-target network of SMT. Green hexagons and red rectangles indicate the four herbal medicines comprising SMT and their 16 active chemical compounds, respectively. Ovals indicate the 230 targets of the active compounds in SMT, while those closely related to myelosuppression are colored in blue.

tissues and organs, which were identified from The Human Protein Atlas [88] and BioGPS databases [90] and analyzed as previously described [91-98] (Figure 5; see Materials and Methods). Consequently, we found that the targets were expressed in various hematopoietic tissues and organs $[129,130]$, including the liver (degree $=144)$, bone marrow $($ degree $=137)$, spleen $\quad($ degree $=116), \quad$ lymph nodes $($ degree $=113)$, and blood $($ degree $=100)($ Figure 5), which suggests the systematic mechanism of action responsible for the pharmacological effects of SMT. Furthermore, all the myelosuppression-associated SMT targets (except ADH1C, AKR1B10, CTNNB1, and CYP17A1) were expressed in two or more tissues and organs, implying that they are closely related to hematopoietic regulation (Figure 5).
Taken together, our findings demonstrate the pharmacological mechanism of action of SMT at a complex network-level.

3.5. Functional Enrichment Analysis of the SMT-Associated Network. To explore the functional roles of the myelosuppression-associated targets of SMT, we conducted gene ontology (GO) enrichment analysis of the targets. We found significant enrichment of the targets in GO terms associated with the regulation of diverse biological processes such as hemopoiesis, cell proliferation, cell differentiation, cell cycle process, cell migration, cell apoptosis, immune response, response to iron binding, and inflammation (Supplementary 


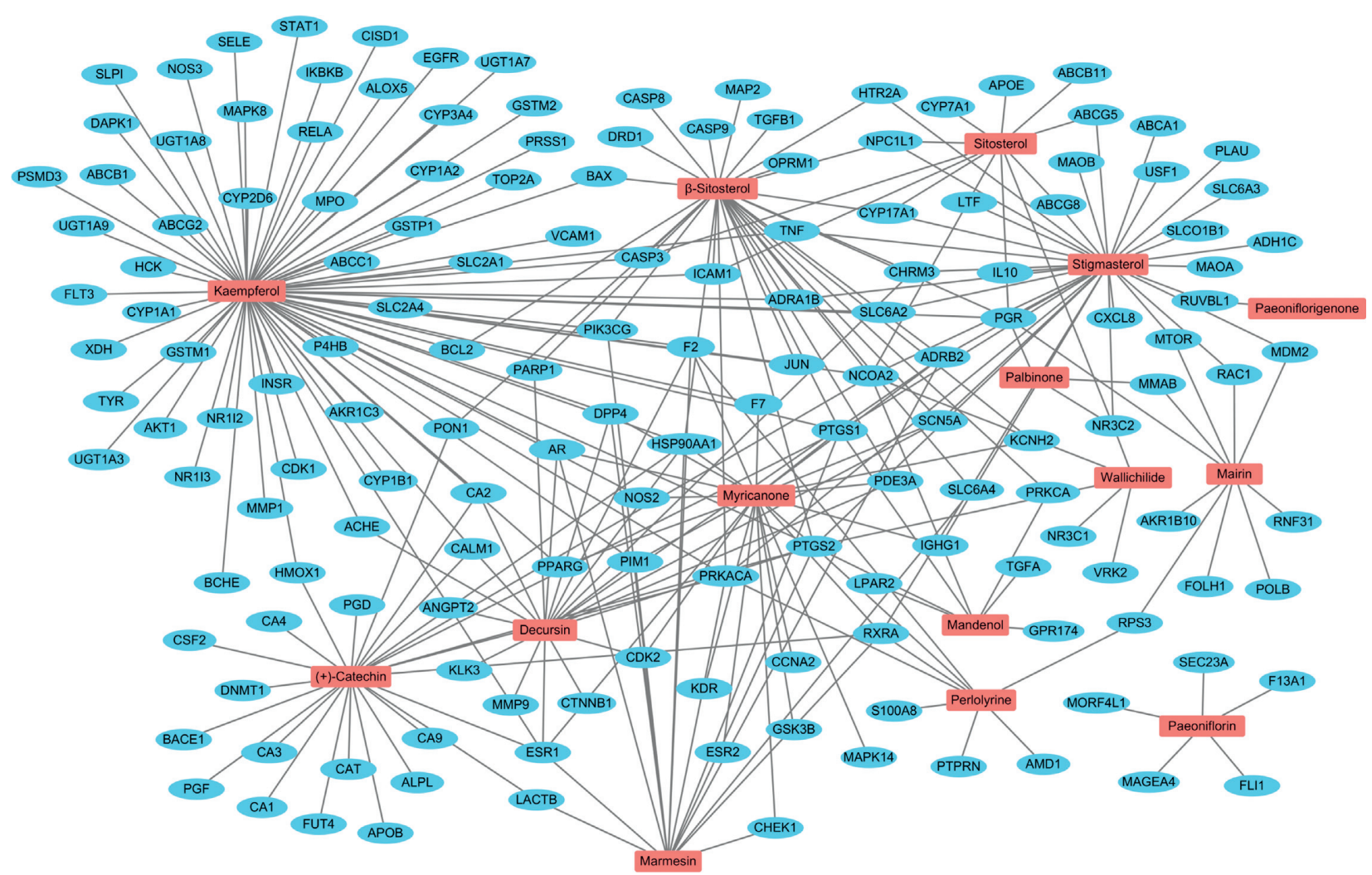

FIGURE 3: The compound-target network of SMT. Red rectangles and blue ovals indicate the 16 active chemical compounds in SMT and their 158 myelosuppression-associated targets, respectively.

Figure S1), which supports the pharmacological mechanisms of SMT hematopoietic activity.

The hematopoietic system is known to be tightly controlled through the precise coordination of various key signaling pathways; further, aberrant regulation of the hematopoiesis-associated pathways could cause various HDs [131-138]. To investigate the pathway-level mechanisms of SMT, we performed KEGG pathway enrichment analysis of its myelosuppression-related targets (Figure 6 and Supplementary Figures S1 and S2). As a result, we found that the targets have relatively large number of connections with the "PI3KAkt signaling pathway" (degree $=23$ ), "MAPK signaling pathway" (degree $=19$ ), "IL-17 signaling pathway" (degree = 16), "TNF signaling pathway" (degree $=15$ ), "Ras signaling pathway" (degree = 15), "HIF-1 signaling pathway" (degree= 12), "FoxO signaling pathway" (degree $=12$ ), "Apoptosis" $($ degree $=12)$, "Cellular senescence" (degree $=12)$, "Toll-like receptor signaling pathway" (degree $=11$ ), "NF-kappa B signaling pathway" (degree $=10)$, "Th17 cell differentiation" $($ degree $=10)$, "p53 signaling pathway" $($ degree $=9)$, "T cell receptor signaling pathway" (degree $=9$ ), "VEGF signaling pathway" (degree=8), and "ErbB signaling pathway" $($ degree $=8)$ (Figure 6 and Supplementary Figures S1 and S2). A substantial body of research has shown that these highly connected signaling pathways may play important roles in hematopoietic regulation and HD pathogenesis. The PI3KAkt, MAPK, Ras, FoxO, HIF-1, Toll-like receptor, NF-kappa B, and VEGF pathways are crucial for the functional modulation of the hematopoietic system; further, their aberrant regulation may contribute to HD development [111, 123, 139-163]. The TNF signaling pathway has been reported as a key regulator for the hematopoietic processes by coordinating the HSC function $[110,131,164,165]$. The p53 signaling pathwaydependent complex interplay between cell cycle control, senescence, and apoptosis is closely involved in the modulation of HSC function and hematopoietic homeostasis [166-171]. Activation of IL-17 (a pro-inflammatory cytokine produced by distinct cluster of differentiation $4^{+}\left[\mathrm{CD} 4^{+}\right]$Thelper 17 [Th17] cells)-associated pathway stimulates granulopoiesis by inducing the proliferation of bone marrow $\mathrm{CD} 34^{+}$cells and their differentiation into granulocytes; moreover, IL-17 inhibition might impair hematopoietic recovery and deteriorate myelotoxicity caused by radiation injury [172-182].

We further investigated the functional relationship of the myelosuppression-associated targets of SMT using GeneMANIA [183], a web server for investigating and analyzing functional interactions between multiple genes and proteins based on comprehensive biological data integration. The GeneMANIA analysis indicated that among the targets, $40.62 \%$ and $29.88 \%$ were predicted to be co-expressed and to have physical interactions, respectively (Supplementary Figure S3), which suggested a similarity of biological functions and activities exerted by the targets.

Collectively, our findings indicate that SMT might exert its therapeutic activities by modulating multiple myelosuppression-associated signaling pathways and relevant cellular processes. 


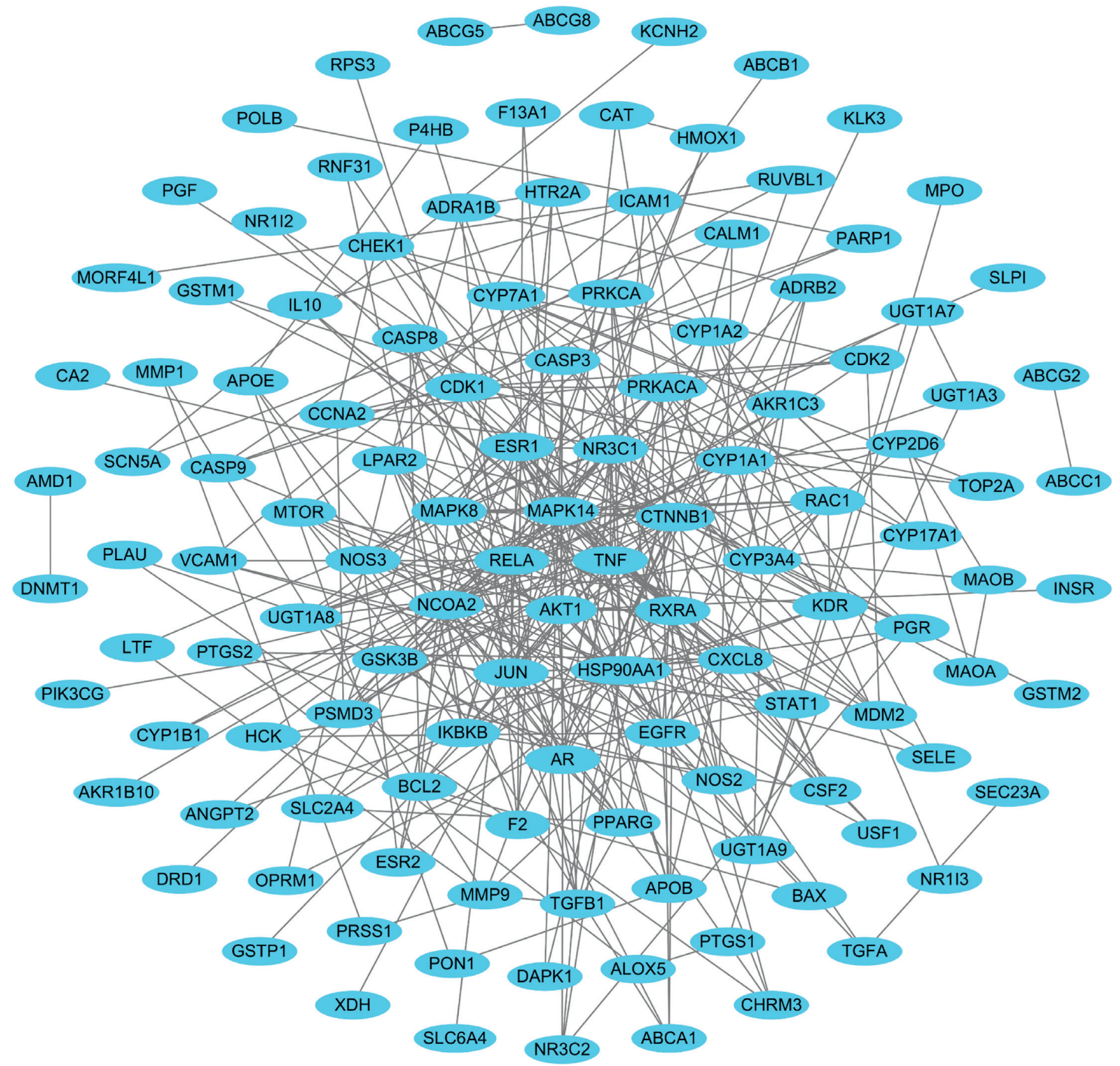

FIGURE 4: The protein-protein interaction network for myelosuppression-associated targets of SMT. Blue ovals indicate the myelosuppression-associated targets of the active chemical compounds in SMT.

\section{Discussion}

Hematopoiesis is a dynamic developmental process that involves the complex regulation of multiple cellular mechanisms in HSCs, including proliferation, self-renewal, differentiation, and apoptosis, to generate a sufficient number of blood cells required to maintain homeostasis of human physiological functions $[1,2]$. Impairment and dysregulation of the hematopoietic system might contribute to the development of various HDs, including myelosuppression [3-5]. There has been increasing attention toward herbal medicines as therapeutic agents for HDs given their effective hematopoietic activities and less side effects [18-23]. In this study, we explored the system-level pharmacological mechanisms underlying the hematopoietic effects of SMT by employing a network pharmacology approach $[47,184]$. The following are our key findings: (i) 16 potentially active phytochemical compounds present in SMT may interact with 158 myelosuppression-related targets to exhibit therapeutic activities; (ii) GO enrichment analysis demonstrated that the targets of the active compounds in SMT were involved in diverse hematopoiesis-associated biological processes such as cell proliferation, cell differentiation, cell cycle process, cell migration, cell apoptosis, immune response, response to iron binding, inflammation, and hemopoiesis; (iii) the myelosuppression-associated targets of SMT were significantly enriched in various pathways, including the PI3K-Akt, MAPK, IL-17, TNF, FoxO, HIF-1, NF-kappa B, and p53 signaling pathways, which are associated with the hematopoiesis and HD development.

SMT is comprised of four herbal medicines (i.e., AGR, RRP, PRA, and CR) containing 16 active phytochemical compounds that interact with 158 myelosuppression-related 


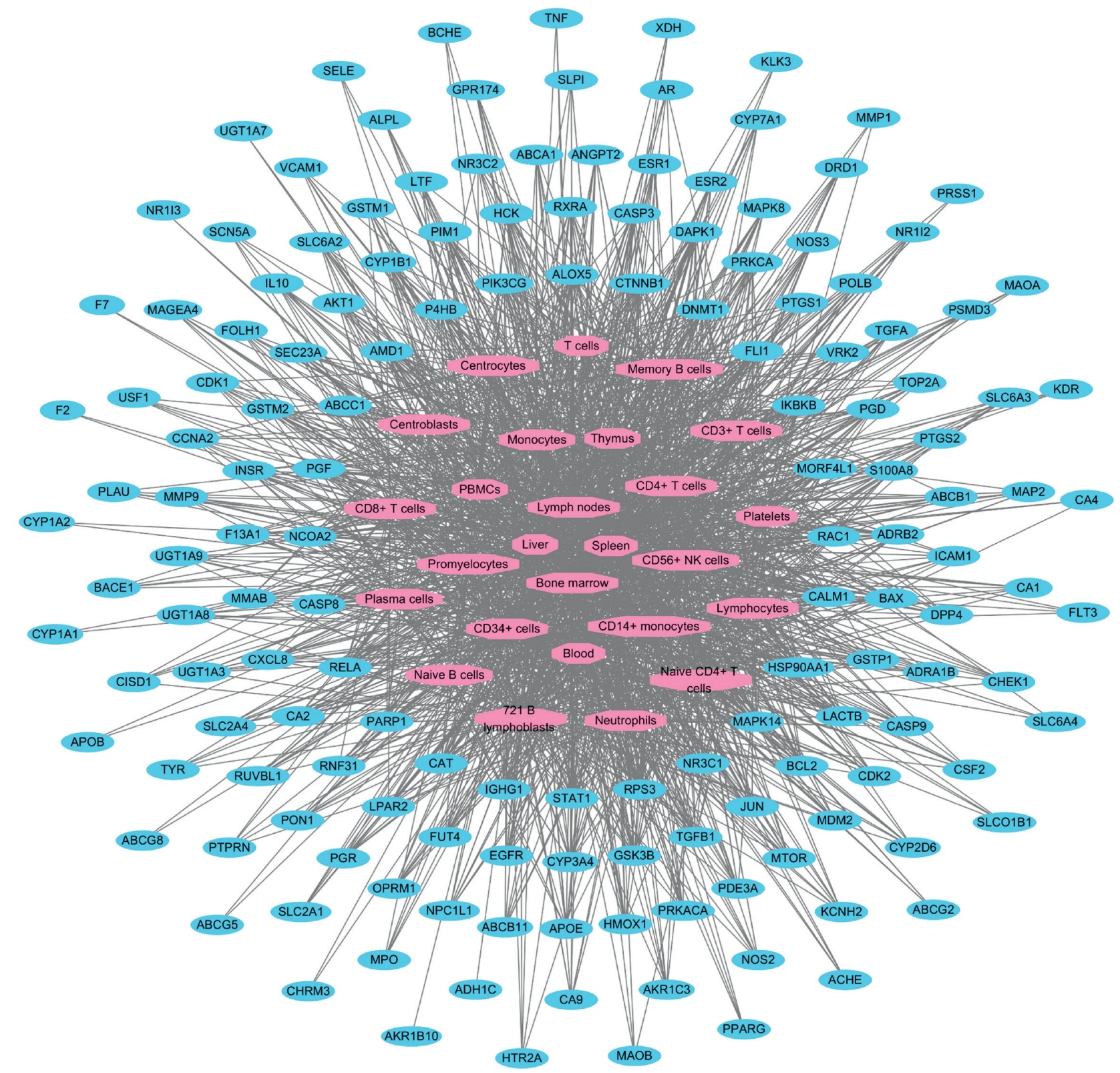

FIGURE 5: The target location network for myelosuppression-associated targets SMT. Pink octagons represent tissues and organs, while blue ovals represent the myelosuppression-associated targets of the active chemical compounds in SMT.

targets as investigated by the network pharmacological approach. These herbal and chemical constituents of SMT have been reported to improve hematopoietic function, and therefore alleviate myelosuppression. AGR and PRA have been reported to ameliorate immunosuppression and hematopoietic dysfunction induced by cyclophosphamide treatment, which is a bone marrow-suppressive cytotoxic alkylating agent $[185,186]$. RRP, $\beta$-sitosterol, and kaempferol are known to possess hematopoietic and immunomodulatory properties in vitro and in vivo [187-191]. $(+)$-catechin stimulates the proliferation of bone marrow cells and thereby exerts protective effects against myelosuppression induced by chemotherapeutic agents in mice [192]. Moreover, paeoniflorin has a hematopoietic activity and promotes the recovery of bone marrow function in radiotherapy-induced myelosuppressed mice via the upregulation of G-CSF and GM-CSF [193]. Taken together, these previous findings support the hematopoietic and immunomodulatory effects of the herbal and chemical constituents of SMT.

Previous experimental studies have demonstrated the hematopoietic role of SMT. For instance, SMT has been reported to stimulate spleen colony formation and to suppress radiation- and chemotherapeutic agent-induced hematopoietic cell injury, thereby exerting a hematopoiesispromoting and myeloprotective effect [42, 194-197]. SMT treatment has also been reported to increase the number of peripheral blood cells and to enhance hematopoietic gene expression, including EPO, G-CSF, CD34, and NF-kappa B, in the bone marrow of the blood-deficiency mice model 


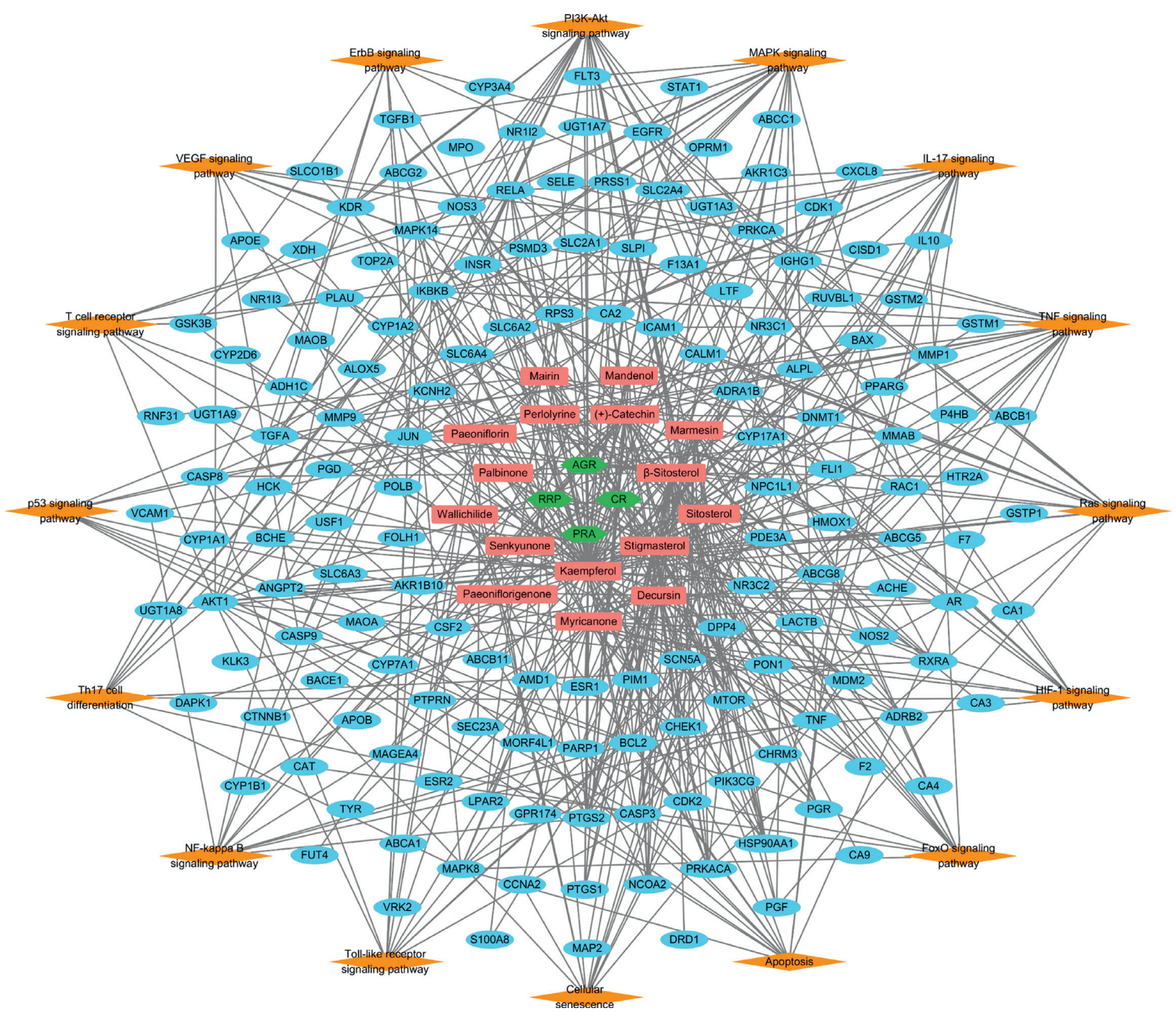

Figure 6: The herb-compound-target-pathway network of SMT. Green hexagons and red rectangles represent the four herbal medicines comprising SMT and their 16 active chemical compounds, respectively. Blue ovals indicate the myelosuppression-associated targets of the active compounds while orange diamonds indicate the signaling pathways enriched with the corresponding targets.

[44, 196, 198-201]. Furthermore, SMT has been shown to increase the amount of erythrocytes and leukocytes as well as the concentration of hemoglobin and hematocrit in blood, and promote the proliferation, cell cycle progression, and differentiation of bone marrow cells [202, 203]. T cell-mediated immunity was decreased in mice injected with antitumor drugs, which was improved by the SMT administration [204]. Further experimental studies are warranted to confirm the therapeutic properties of SMT indicated in this study, which might promote the development of effective herbal medicine-based therapies for treatment of myelosuppression.

\section{Conclusions}

In this study, we explored the system-level pharmacological properties of SMT. Network pharmacology analysis investigated 16 potential active phytochemical compounds of SMT that may interact with 158 myelosuppression- associated targets to exert therapeutic effects. The targets were involved in a variety of hematopoiesis-associated biological processes such as cell proliferation, cell differentiation, cell cycle process, cell migration, cell apoptosis, immune response, inflammation, response to iron binding, and hemopoiesis. We further found that the targets of SMT were enriched in various signaling pathways related to the hematopoiesis and myelosuppression development, including the PI3K-Akt, MAPK, IL-17, TNF, FoxO, HIF-1, NF-kappa B, and p53 signaling pathways. In conclusion, our study provides a novel insight into the synergistic and polypharmacological action mechanisms of herbal medicines for the HD treatment.

\section{Abbreviations}

ADME: $\quad$ Absorption, distribution, metabolism, and excretion

AGR: $\quad$ Angelicae gigantis radix 


\begin{tabular}{|c|c|}
\hline AR: & Androgen receptor \\
\hline CR: & Cnidii rhizoma \\
\hline C-T: & Compound-target \\
\hline CTD: & The Comparative Toxicogenomics Database \\
\hline CTNNB1: & Catenin beta-1 \\
\hline CXCL8: & Chemokine (C-X-C motif) ligand 8 \\
\hline CYP1A1: & $\begin{array}{l}\text { Cytochrome P450 family } 1 \text { subfamily A } \\
\text { member } 1\end{array}$ \\
\hline CYP3A4: & $\begin{array}{l}\text { Cytochrome P450 family } 3 \text { subfamily A } \\
\text { member } 4\end{array}$ \\
\hline CD34: & Cluster of differentiation 34 \\
\hline CD4: & Cluster of differentiation 4 \\
\hline DL: & Drug-likeness \\
\hline EGFR: & Epidermal growth factor receptor \\
\hline EPO: & Erythropoietin \\
\hline ESRA: & Estrogen receptor alpha \\
\hline FoxO: & Forkhead box protein $\mathrm{O}$ \\
\hline G-CSF: & Granulocyte-colony-stimulating factor \\
\hline GO: & Gene ontology \\
\hline GM-CSF: & $\begin{array}{l}\text { Granulocyte-macrophage colony-stimulating } \\
\text { factor }\end{array}$ \\
\hline $\mathrm{H}-\mathrm{C}:$ & Herb-compound \\
\hline H-C-T: & Herb-target-pathway \\
\hline HD: & Hematological disorder \\
\hline HIF-1: & Hypoxia-inducible factor 1 \\
\hline HIT: & Herb Ingredients' Targets \\
\hline HSC: & Hematopoietic stem cell \\
\hline HSP90AA1: & $\begin{array}{l}\text { Heat shock protein } 90 \text { alpha family class } A \\
\text { member } 1\end{array}$ \\
\hline HuGE & Human Genome Epidemiology Navigator \\
\hline Navigator: & \\
\hline IL: & Interleukin \\
\hline IFN: & Interferon \\
\hline KEGG: & Kyoto Encyclopedia of Genes and Genomes \\
\hline MAPK: & Mitogen-activated protein kinase \\
\hline NCOA2: & Nuclear receptor coactivator 2 \\
\hline NF-kappa B: & $\begin{array}{l}\text { Nuclear factor kappa-light-chain-enhancer } \\
\text { of activated B cells }\end{array}$ \\
\hline NR3C1: & $\begin{array}{l}\text { Nuclear receptor subfamily } 3 \text { group C } \\
\text { member } 1\end{array}$ \\
\hline OB: & Oral bioavailability \\
\hline OMIM: & Online Mendelian Inheritance in Man \\
\hline PharmGKB: & $\begin{array}{l}\text { Pharmacogenomics Knowledge for } \\
\text { Personalized Medicine }\end{array}$ \\
\hline PI3K: & Phosphoinositide 3-kinase \\
\hline PPI: & Protein-protein interaction \\
\hline PRA: & Paeoniae radix alba \\
\hline PRKACA: & $\begin{array}{l}\text { Protein kinase cAMP-activated catalytic } \\
\text { subunit alpha }\end{array}$ \\
\hline RELA: & $\begin{array}{l}\text { v-rel avian reticuloendotheliosis viral } \\
\text { oncogene homolog A }\end{array}$ \\
\hline RRP: & Rehmanniae radix preparata \\
\hline RXRA: & Retinoid X receptor alpha \\
\hline SEA: & Similarity Ensemble Approach \\
\hline SMT: & Samul-tang \\
\hline STITCH: & Search Tool for Interactions of Chemicals \\
\hline SysDT: & Systematic drug targeting tool \\
\hline TCM: & Traditional Chinese medicine \\
\hline
\end{tabular}

$\begin{array}{ll}\text { TCMID: } & \text { Traditional Chinese Medicine Integrated } \\ & \text { Database } \\ \text { TCMSP: } & \text { Traditional Chinese Medicine Systems } \\ & \text { Pharmacology } \\ \text { Th17 cells: } & \text { T helper } 17 \text { cells } \\ \text { TTD: } & \text { Therapeutic Target Database } \\ \text { TNF: } & \text { Tumor necrosis factor } \\ \text { T-P: } & \text { Target-pathway } \\ \text { WES } & \text { Weighted ensemble similarity algorithm. } \\ \text { algorithm: } & \end{array}$

\section{Data Availability}

The data used to support the findings of this study are included within the article.

\section{Conflicts of Interest}

The authors declare that there are no conflicts of interest regarding the publication of this paper.

\section{Acknowledgments}

The authors thank Wan-Su Kim, Young-Woo Yi, and Juhwi Jo for their kind assistance with data acquisition. The authors would also like to thank Editage (http://www.editage.com) for English language editing. This study was funded by The Fore and Forest Hospital.

\section{Supplementary Materials}

Supplementary Figure S1: functional enrichment analysis of the myelosuppression-related targets of SMT. Supplementary Figure S2: pathway enrichment analysis of the myelosuppression-related targets of SMT. Supplementary Figure S3: functional interaction analysis of the myelosuppressionrelated targets of SMT. Supplementary Table S1: molecular properties of chemical compounds in SMT. Supplementary Table S2: molecular properties of active chemical compounds in SMT. Supplementary Table S3: list of the targets of active chemical compounds in SMT. (Supplementary Materials)

\section{References}

[1] S. Pinho and P. S. Frenette, "Haematopoietic stem cell activity and interactions with the niche," Nature Reviews Molecular Cell Biology, vol. 20, no. 5, pp. 303-320, 2019.

[2] A. Mendelson and P. S. Frenette, "Hematopoietic stem cell niche maintenance during homeostasis and regeneration," Nature Medicine, vol. 20, no. 8, pp. 833-846, 2014.

[3] J. A. Gilreath, D. D. Stenehjem, and G. M. Rodgers, "Diagnosis and treatment of cancer-related anemia," American Journal of Hematology, vol. 89, no. 2, pp. 203-212, 2014.

[4] P. J. Carey, "Drug-induced myelosuppression: diagnosis and management," Drug Safety, vol. 26, no. 10, pp. 691-706, 2003.

[5] M. B. Maxwell and K. E. Maher, "Chemotherapy-induced myelosuppression," Seminars in Oncology Nursing, vol. 8, no. 2, pp. 113-123, 1992. 
[6] G. Wu, Y. Zhou, L. Li et al., "Platelet immunology in China: research and clinical applications," Transfusion Medicine Reviews, vol. 31, no. 2, pp. 118-125, 2017.

[7] R. L. Gauer and M. M. Braun, "Thrombocytopenia," American Family Physician, vol. 85, no. 6, pp. 612-622, 2012.

[8] B. V. Fortner and A. C. Houts, "Greater physical and psychological symptom burden in patients with grade $3 / 4$ chemotherapy-induced neutropenia," Supportive Cancer Therapy, vol. 3, no. 3, pp. 173-177, 2006.

[9] H. Ludwig and K. Strasser, "Symptomatology of anemia," Seminars in Oncology, vol. 28, no. 2, pp. 7-14, 2001.

[10] M. S. Aapro, J. Bohlius, D. A. Cameron et al., "2010 update of EORTC guidelines for the use of granulocyte-colony stimulating factor to reduce the incidence of chemotherapyinduced febrile neutropenia in adult patients with lymphoproliferative disorders and solid tumours," European Journal of Cancer, vol. 47, no. 1, pp. 8-32, 2011.

[11] G. D. Demetri, M. Kris, J. Wade, L. Degos, and D. Cella, "Quality-of-life benefit in chemotherapy patients treated with epoetin alfa is independent of disease response or tumor type: results from a prospective community oncology study. Procrit Study Group," Journal of Clinical Oncology, vol. 16, no. 10, pp. 3412-3425, 1998.

[12] G. J. Lieschke and A. W. Burgess, "Granulocyte colonystimulating factor and granulocyte-macrophage colonystimulating factor," The New England Journal of Medicine, vol. 327, no. 1, pp. 28-35, 1992.

[13] H. Ozer, J. O. Armitage, C. L. Bennett et al., "2000 update of recommendations for the use of hematopoietic colonystimulating factors: evidence-based, clinical practice guidelines," Journal of Clinical Oncology, vol. 18, no. 20, pp. 3558-3585, 2000.

[14] H. Khoury, D. Adkins, R. Brown et al., "Adverse side-effects associated with G-CSF in patients with chronic myeloid leukemia undergoing allogeneic peripheral blood stem cell transplantation," Bone Marrow Transplantation, vol. 25, no. 11, pp. 1197-1201, 2000.

[15] P. Gu and H. Chen, "Modern bioinformatics meets traditional Chinese medicine," Briefings in Bioinformatics, vol. 15, no. 6, pp. 984-1003, 2014.

[16] G. B. Zhang, Q. Y. Li, Q. L. Chen, and S. B. Su, "Network pharmacology: a new approach for Chinese herbal medicine research," Evidence-Based Complementary and Alternative Medicine, vol. 2013, Article ID 621423, 9 pages, 2013.

[17] C. Huang, C. Zheng, Y. Li, Y. Wang, A. Lu, and L. Yang, "Systems pharmacology in drug discovery and therapeutic insight for herbal medicines," Briefings in Bioinformatics, vol. 15, no. 5, pp. 710-733, 2014.

[18] Y. Zhang, T. Ye, Z. Hong et al., "Pharmacological and transcriptome profiling analyses of Fufang E'jiao Jiang during chemotherapy-induced myelosuppression in mice," Journal of Ethnopharmacology, vol. 238, Article ID 111869, 2019.

[19] H. Tian, W. Qin, W. Wu et al., "Effects of traditional Chinese medicine on chemotherapy-induced myelosuppression and febrile neutropenia in breast cancer patients," EvidenceBased Complementary and Alternative Medicine, vol. 2015, Article ID 736197, 11 pages, 2015.

[20] Y. Jia, H. Du, M. Yao et al., "Chinese herbal medicine for myelosuppression induced by chemotherapy or radiotherapy: a systematic review of randomized controlled trials," Evidence-Based Complementary and Alternative Medicine, vol. 2015, Article ID 690976, 12 pages, 2015.
[21] K. Ogawa, T. Omatsu, C. Matsumoto et al., "Protective effect of the Japanese traditional medicine juzentaihoto on myelosuppression induced by the anticancer drug TS- 1 and identification of a potential biomarker of this effect," $B M C$ Complementary and Alternative Medicine, vol. 12, no. 1, p. 118, 2012.

[22] Z. Rui, Y. U. Tang-Yao, and W. U. Bin, “A systematic review of Garden burnet root leukopoietic tablets treatment and prevention of radiotherapy-induced leukopenia," Chinese Journal of Hospital Pharmacy, vol. 9, pp. 719-722, 2012.

[23] X. Chen, B. Li, Y. Gao, J. Ji, Z. Wu, and S. Chen, "Saponins from sanguisorba officinalis improve hematopoiesis by promoting survival through FAK and erk1/2 activation and modulating cytokine production in bone marrow," Frontiers in Pharmacology, vol. 8, p. 130, 2017.

[24] L. Jia, S. Ma, X. Hou et al., "The synergistic effects of traditional Chinese herbs and radiotherapy for cancer treatment," Oncology Letters, vol. 5, no. 5, pp. 1439-1447, 2013.

[25] P. Y. Gong, Y. S. Tian, Y. J. Guo et al., "Comparisons of antithrombosis, hematopoietic effects and chemical profiles of dried and rice wine-processed Rehmanniae radix extracts," Journal of Ethnopharmacology, vol. 231, pp. 394-402, 2019.

[26] H. Wu, C. Ren, F. Yang, Y. Qin, Y. Zhang, and J. Liu, "Extraction and identification of collagen-derived peptides with hematopoietic activity from Colla Corii Asini," Journal of Ethnopharmacology, vol. 182, pp. 129-136, 2016.

[27] P. L. Li, H. G. Sun, Y. L. Hua et al., "Metabolomics study of hematopoietic function of Angelica sinensis on blood deficiency mice model," Journal of Ethnopharmacology, vol. 166, pp. 261-269, 2015.

[28] M. Liu, H. Tan, X. Zhang et al., "Hematopoietic effects and mechanisms of Fufang E'jiao Jiang on radiotherapy and chemotherapy-induced myelosuppressed mice," Journal of Ethnopharmacology, vol. 152, no. 3, pp. 575-584, 2014.

[29] J. G. Lee, W. T. Hsieh, S. U. Chen, and B. H. Chiang, "Hematopoietic and myeloprotective activities of an acidic Angelica sinensis polysaccharide on human $\mathrm{CD} 34^{+}$stem cells," Journal of Ethnopharmacology, vol. 139, no. 3, pp. 739-745, 2012.

[30] W. C. You, W. C. Lin, J. T. Huang, and C. C. Hsieh, "Indigowood root extract protects hematopoietic cells, reduces tissue damage and modulates inflammatory cytokines after total-body irradiation: does Indirubin play a role in radioprotection?" Phytomedicine, vol. 16, no. 12, pp. 1105-1111, 2009.

[31] M. L. Queiroz, M. C. Valadares, C. O. Torello et al., "Comparative studies of the effects of Tabebuia avellanedae bark extract and $\beta$-lapachone on the hematopoietic response of tumour-bearing mice," Journal of Ethnopharmacology, vol. 117 , no. 2 , pp. $228-235,2008$

[32] T. Hong, T. Matsumoto, H. Kiyohara, and H. Yamada, "Enhanced production of hematopoietic growth factors through $\mathrm{T}$ cell activation in Peyer's patches by oral administration of Kampo (Japanese herbal) medicine, "JuzenTaiho-To"," Phytomedicine, vol. 5, no. 5, pp. 353-360, 1998.

[33] H. Y. Hsu, J. J. Yang, S. L. Lian, Y. H. Ho, and C. C. Lin, "Recovery of the hematopoietic system by Si-Jun-Zi-Tang in whole body irradiated mice," Journal of Ethnopharmacology, vol. 54, no. 2-3, pp. 69-75, 1996.

[34] E. S. Choi, J. J. Yoon, B. H. Han et al., "Samul-tang regulates cell cycle and migration of vascular smooth muscle cells against TNF- $\alpha$ stimulation," Evidence-Based Complementary 
and Alternative Medicine, vol. 2018, Article ID 1024974, 9 pages, 2018.

[35] E. S. Choi, Y. J. Lee, C. S. Seo et al., "Vascular protective role of samul-tang in HUVECs: involvement of Nrf2/HO-1 and NO," Evidence-Based Complementary and Alternative Medicine, vol. 2016, Article ID 9580234, 14 pages, 2016.

[36] H. W. Lee, H. Kim, J. A. Ryuk, K. J. Kil, and B. S. Ko, "Hemopoietic effect of extracts from constituent herbal medicines of Samul-tang on phenylhydrazine-induced hemolytic anemia in rats," International Journal of Clinical and Experimental Pathology, vol. 7, no. 9, pp. 6179-6185, 2014.

[37] L. L. Yeh, J. Y. Liu, Y. S. Liu, K. S. Lin, T. F. Tsai, and L. H. Wang, "Anemia-related hemogram, uterine artery pulsatility index, and blood pressure for the effects of FourAgents-Decoction (Si Wu Tang) in the treatment of primary dysmenorrhea," The Journal of Alternative and Complementary Medicine, vol. 15, no. 5, pp. 531-538, 2009.

[38] L. Li, D. Jin'ao, L. Pei et al., "Study on compare Taohong Siwu decoction, taoren-Honghua pair and Siwu decoction for primary dysmenorrhea," Pharmacology and Clinics of Chinese Materia Medica, vol. 1, 2012.

[39] C. Zhang, Y. Lu, J. Duan, S. Su, Y. Tang, and E. Shang, "Study on Siwu decoction and its serial decoctions in dysmenorrhea model mice," Pharmaceutical and Clinical Research, vol. 15, pp. 459-461, 2010.

[40] Y. Hua, J. Duan, S. Su, Y. Lu, Q. Wang, and Y. Tang, "Bioactivity evaluation of Siwu Decoction and its derived formulaes in the treatment of primary dysmenorrhea," Journal of China Pharmaceutical University, vol. 39, no. 1, p. 72, 2008.

[41] H. J. Kang, S. J. Park, C. K. Cho, Y. W. Lee, and H. S. Yoo, "Recovery from chemotherapy induced neutropenia treated with Samul-tanggagambang," Korean Journal of Oriental Physiology \& Pathology, vol. 29, no. 1, pp. 85-89, 2015.

[42] H. Y. Hsu, Y. H. Ho, and C. C. Lin, "Protection of mouse bone marrow by $\mathrm{Si}-\mathrm{Wu}$-Tang against whole body irradiation," Journal of Ethnopharmacology, vol. 52, no. 2, pp. 113-117, 1996.

[43] G. C. Huang, Y. Z. Tsai, C. J. Lee, H. Y. Chang, and C. C. Wang, "Elucidation of the effects of Si-Wu Tang on menstrual disorder patterns through activation of aromatase and antioxidation," Evidence-Based Complementary and Alternative Medicine, vol. 2019, Article ID 4761651, 8 pages, 2019.

[44] P. Guo, Q. D. Liang, J. J. Hu, J. F. Wang, and S. Q. Wang, "The effect of Siwu Tang on EPO and G-CSF gene expression in bone marrow of irradiated blood deficiency mice," Zhongguo Zhong Yao Za Zhi, vol. 30, no. 15, pp. 1173-1176, 2005.

[45] Q. D. Liang, X. Q. Lu, Z. C. Ma et al., "Preliminary study on hematopoietic constituents of Si-Wu-Tang," Zhongguo Zhong Yao Za Zhi, vol. 29, no. 6, pp. 546-549, 2004.

[46] H.-R. Park, S.-H. Kim, S.-T. Yee, M.-W. Byun, and S.-K. Jo, "Effect of a herb mixture (HIM-I) on the protection of the hematopoietic-immune system and self-renewal tissues against radiation damage," Journal of the Korean Society of Food Science and Nutrition, vol. 34, no. 5, pp. 605-612, 2005.

[47] P. Poornima, J. D. Kumar, Q. Zhao, M. Blunder, and T. Efferth, "Network pharmacology of cancer: from understanding of complex interactomes to the design of multitarget specific therapeutics from nature," Pharmacological Research, vol. 111, pp. 290-302, 2016.
[48] C. D. Hao and P. G. Xiao, "Network pharmacology: a Rosetta Stone for traditional Chinese medicine," Drug Development Research, vol. 75, no. 5, pp. 299-312, 2014.

[49] L. Huang, D. Xie, Y. Yu et al., "Tcmid 2.0: a comprehensive resource for TCM," Nucleic Acids Research, vol. 46, no. D1, pp. D1117-D1120, 2018.

[50] R. Xue, Z. Fang, M. Zhang, Z. Yi, C. Wen, and T. Shi, "TCMID: traditional Chinese medicine integrative database for herb molecular mechanism analysis," Nucleic Acids Research, vol. 41, pp. D1089-D1095, 2012.

[51] H. Ye, L. Ye, H. Kang et al., "HIT: linking herbal active ingredients to targets," Nucleic Acids Research, vol. 39, pp. D1055-D1059, 2011.

[52] J. Ru, P. Li, J. Wang et al., "TCMSP: a database of systems pharmacology for drug discovery from herbal medicines," Journal of Cheminformatics, vol. 6, p. 13, 2014.

[53] S. Ok, S. R. Oh, T. S. Jung, S. O. Jeon, J. W. Jung, and D. S. Ryu, "Effects of Angelica gigasnakai as an anti-inflammatory agent in in vitro and in vivo atopic dermatitis models," Evidence-Based Complementary and Alternative Medicine, vol. 2018, Article ID 2450712, 12 pages, 2018.

[54] S. Y. Jeong, H. M. Kim, K. H. Lee et al., "Quantitative analysis of marker compounds in Angelica gigas, Angelica sinensis, and Angelica acutiloba by HPLC/DAD," Chemical and Pharmaceutical Bulletin, vol. 63, no. 7, pp. 504-511, 2015.

[55] M. R. Kim, A. M. Abd El-Aty, I. S. Kim, and J. H. Shim, "Determination of volatile flavor components in danggui cultivars by solvent free injection and hydrodistillation followed by gas chromatographic-mass spectrometric analysis," Journal of Chromatography A, vol. 1116, no. 1-2, pp. 259-264, 2006.

[56] C. K. Wang and D. J. Craik, "Cyclic peptide oral bioavailability: lessons from the past," Biopolymers, vol. 106, no. 6, pp. 901-909, 2016.

[57] Y. Kono, A. Iwasaki, K. Matsuoka, and T. Fujita, "Effect of mechanical agitation on cationic liposome transport across an unstirred water layer in Caco-2 cells," Biological \& Pharmaceutical Bulletin, vol. 39, no. 8, pp. 1293-1299, 2016.

[58] D. A. Volpe, "Variability in Caco-2 and MDCK cell-based intestinal permeability assays," Journal of Pharmaceutical Sciences, vol. 97, no. 2, pp. 712-725, 2008.

[59] M. N. Garcia, C. Flowers, and J. D. Cook, "The Caco-2 cell culture system can be used as a model to study food iron availability," The Journal of Nutrition, vol. 126, no. 1, pp. 251-258, 1996.

[60] Y. Li, J. Zhang, L. Zhang et al., "Systems pharmacology to decipher the combinational anti-migraine effects of Tianshu formula," Journal of Ethnopharmacology, vol. 174, pp. 45-56, 2015.

[61] J. Zhang, Y. Li, X. Chen, Y. Pan, S. Zhang, and Y. Wang, "Systems pharmacology dissection of multi-scale mechanisms of action for herbal medicines in stroke treatment and prevention," PLoS One, vol. 9, no. 8, Article ID e102506, 2014.

[62] A. Y. Lee, W. Park, T. W. Kang, M. H. Cha, and J. M. Chun, "Network pharmacology-based prediction of active compounds and molecular targets in Yijin-Tang acting on hyperlipidaemia and atherosclerosis," Journal of Ethnopharmacology, vol. 221, pp. 151-159, 2018.

[63] J. Huang, F. Cheung, H. Y. Tan et al., "Identification of the active compounds and significant pathways of Yinchenhao decoction based on network pharmacology," Molecular Medicine Reports, vol. 16, no. 4, pp. 4583-4592, 2017. 
[64] S. J. Yue, L. T. Xin, Y. C. Fan et al., "Herb pair DangguiHonghua: mechanisms underlying blood stasis syndrome by system pharmacology approach," Scientific Reports, vol. 7, p. $40318,2017$.

[65] D. Szklarczyk, A. Santos, C. von Mering, L. J. Jensen, P. Bork, and M. Kuhn, "Stitch 5: augmenting protein-chemical interaction networks with tissue and affinity data," Nucleic Acids Research, vol. 44, no. D1, pp. D380-D384, 2016.

[66] M. J. Keiser, B. L. Roth, B. N. Armbruster, P. Ernsberger, J. J. Irwin, and B. K. Shoichet, "Relating protein pharmacology by ligand chemistry," Nature Biotechnology, vol. 25, no. 2, pp. 197-206, 2007.

[67] A. Daina, O. Michielin, and V. Zoete, "SwissTargetPrediction: updated data and new features for efficient prediction of protein targets of small molecules," Nucleic Acids Research, vol. 47, no. W1, pp. W357-W364, 2019.

[68] D. Gfeller, A. Grosdidier, M. Wirth, A. Daina, O. Michielin, and V. Zoete, "SwissTargetPrediction: a web server for target prediction of bioactive small molecules," Nucleic Acids Research, vol. 42, pp. W32-W38, 2014.

[69] X. Wang, Y. Shen, S. Wang et al., "PharmMapper 2017 update: a web server for potential drug target identification with a comprehensive target pharmacophore database," Nucleic Acids Research, vol. 45, no. W1, pp. W356-W360, 2017.

[70] H. Yu, J. Chen, X. Xu et al., "A systematic prediction of multiple drug-target interactions from chemical, genomic, and pharmacological data," PLoS One, vol. 7, no. 5, Article ID e37608, 2012.

[71] C. Zheng, Z. Guo, C. Huang et al., "Large-scale direct targeting for drug repositioning and discovery," Scientific Reports, vol. 5, p. 11970, 2015.

[72] J. Liu, M. Jiang, Z. Li et al., "A novel systems pharmacology method to investigate molecular mechanisms of scutellaria barbata D. don for non-small cell lung cancer," Frontiers in Pharmacology, vol. 9, p. 1473, 2018.

[73] X. Su, Y. Li, M. Jiang et al., "Systems pharmacology uncover the mechanism of anti-non-small cell lung cancer for Hedyotis diffusa willd," Biomedicine \& Pharmacotherapy, vol. 109, pp. 969-984, 2019.

[74] J. Wang, L. Zhang, B. Liu et al., "Systematic investigation of the Erigeron breviscapus mechanism for treating cerebrovascular disease," Journal of Ethnopharmacology, vol. 224, pp. 429-440, 2018.

[75] J. Liu, F. Shen, Z. Qin et al., "Systems pharmacology analysis of synergy of TCM: an example using saffron formula," Scientific Reports, vol. 8, no. 1, p. 380, 2018.

[76] J. Liu, J. Zhu, J. Xue et al., "In silico-based screen synergistic drug combinations from herb medicines: a case using Cistanche tubulosa," Scientific Reports, vol. 7, no. 1, p. 16364, 2107.

[77] J. Liu, T. Pei, J. Mu et al., "Systems pharmacology uncovers the multiple mechanisms of Xijiao Dihuang decoction for the treatment of viral hemorrhagic fever," Evidence-Based Complementary and Alternative Medicine, vol. 2016, Article ID 9025036, 17 pages, 2016.

[78] Y. Yang, C. Huang, X. Su et al., "Deciphering the multicomponent synergy mechanism from a systems pharmacology perspective: application to Gualou Xiebai decoction for coronary heart disease," Journal of Functional Foods, vol. 47, pp. 143-155, 2018.
[79] The UniProt Consortium, "UniProt: the universal protein knowledgebase," Nucleic Acids Research, vol. 46, no. 5, p. 2699, 2018.

[80] J. S. Amberger, C. A. Bocchini, F. Schiettecatte, A. F. Scott, and A. Hamosh, "OMIM.org: online Mendelian inheritance in man (OMIM(R)), an online catalog of human genes and genetic disorders," Nucleic Acids Research, vol. 43, pp. D789-D798, 2015.

[81] F. Zhu, B. Han, P. Kumar et al., "Update of TTD: therapeutic target database," Nucleic Acids Research, vol. 38, pp. D787D791, 2010.

[82] M. Safran, I. Dalah, J. Alexander et al., "GeneCards version 3: the human gene integrator," Database, vol. 2010, Article ID baq020, 2010.

[83] D. S. Wishart, Y. D. Feunang, A. C. Guo et al., "DrugBank 5.0: a major update to the DrugBank database for 2018," Nucleic Acids Research, vol. 46, no. D1, pp. D1074-D1082, 2018.

[84] M. Whirl-Carrillo, E. M. McDonagh, J. M. Hebert et al., "Pharmacogenomics knowledge for personalized medicine," Clinical Pharmacology \& Therapeutics, vol. 92, no. 4, pp. 414-417, 2012.

[85] J. Pinero, A. Bravo, N. Queralt-Rosinach et al., "DisGeNET: a comprehensive platform integrating information on human disease-associated genes and variants," Nucleic Acids Research, vol. 45, no. D1, pp. D833-D839, 2017.

[86] W. Yu, M. Gwinn, M. Clyne, A. Yesupriya, and M. J. Khoury, "A navigator for human genome epidemiology," Nature Genetics, vol. 40, no. 2, pp. 124-125, 2008.

[87] A. P. Davis, C. J. Grondin, R. J. Johnson et al., "The comparative Toxicogenomics database: update 2019," Nucleic Acids Research, vol. 47, no. D1, pp. D948-D954, 2019.

[88] P. Shannon, A. Markiel, O. Ozier et al., "Cytoscape: a software environment for integrated models of biomolecular interaction networks," Genome Research, vol. 13, no. 11, pp. 2498-2504, 2003.

[89] M. Uhlen, L. Fagerberg, B. M. Hallstrom et al., "Proteomics. Tissue-based map of the human proteome," Science, vol. 347, no. 6220, Article ID 1260419, 2015.

[90] C. Wu, C. Orozco, J. Boyer et al., "BioGPS: an extensible and customizable portal for querying and organizing gene annotation resources," Genome Biology, vol. 10, no. 11, p. R130, 2009.

[91] W. J. Lv, C. Liu, Y. F. Li et al., "Systems pharmacology and microbiome dissection of shen ling Bai zhu san reveal multiscale treatment strategy for IBD," Oxidative Medicine and Cellular Longevity, vol. 2019, Article ID 8194804, 30 pages, 2019.

[92] Z. Chen, Y. Cao, Y. Zhang, and Y. Qiao, "A novel discovery: holistic efficacy at the special organ level of pungent flavored compounds from pungent traditional Chinese medicine," International Journal of Molecular Sciences, vol. 20, no. 3, 2019.

[93] Z. Song, F. Yin, B. Xiang, B. Lan, and S. Cheng, "Systems pharmacological approach to investigate the mechanism of Acori tatarinowii rhizoma for Alzheimer's disease," Evidence-Based Complementary and Alternative Medicine, vol. 2018, Article ID 5194016, 20 pages, 2018.

[94] S. Y. Suh and W. G. An, "Systems pharmacological approach to the effect of Bulsu-san promoting parturition," EvidenceBased Complementary and Alternative Medicine, vol. 2017, Article ID 7236436, 15 pages, 2017.

[95] J. Y. Wang, H. Chen, Y. Y. Wang et al., "Network pharmacological mechanisms of Vernonia anthelmintica (L.) in 
the treatment of vitiligo: isorhamnetin induction of melanogenesis via up-regulation of melanin-biosynthetic genes," BMC Systems Biology, vol. 11, no. 1, p. 103, 2017.

[96] S. J. Yue, J. Liu, W. W. Feng et al., "System pharmacologybased dissection of the synergistic mechanism of Huangqi and Huanglian for diabetes mellitus," Frontiers in Pharmacology, vol. 8, p. 694, 2017.

[97] S. Y. Suh and W. G. An, "Systems pharmacological approach of Pulsatillae radix on treating Crohn's disease," EvidenceBased Complementary and Alternative Medicine, vol. 2017, Article ID 4198035, 21 pages, 2017.

[98] Y. Wang, C. Zheng, C. Huang et al., "Systems pharmacology dissecting holistic medicine for treatment of complex diseases: an example using cardiocerebrovascular diseases treated by TCM," Evidence-Based Complementary and Alternative Medicine, vol. 2015, Article ID 980190, 19 pages, 2015.

[99] D. Szklarczyk, A. L. Gable, D. Lyon et al., "STRING v11: protein-protein association networks with increased coverage, supporting functional discovery in genome-wide experimental datasets," Nucleic Acids Research, vol. 47, no. D1, pp. D607-D613, 2019.

[100] A. L. Barabasi and Z. N. Oltvai, "Network biology: understanding the cell's functional organization," Nature Reviews Genetics, vol. 5, no. 2, pp. 101-113, 2004.

[101] J. Reimand, T. Arak, P. Adler et al., "G:profiler-a web server for functional interpretation of gene lists (2016 update)," Nucleic Acids Research, vol. 44, no. W1, pp. W83-W89, 2016.

[102] M. Kanehisa and S. Goto, "KEGG: kyoto encyclopedia of genes and genomes," Nucleic Acids Research, vol. 28, no. 1, pp. 27-30, 2000.

[103] J. Huang, L. Li, F. Cheung et al., "Network pharmacologybased approach to investigate the analgesic efficacy and molecular targets of Xuangui dropping pill for treating primary dysmenorrhea," Evidence-Based Complementary and Alternative Medicine, vol. 2017, Article ID 7525179, 12 pages, 2017.

[104] F. Tang, Q. Tang, Y. Tian, Q. Fan, Y. Huang, and X. Tan, "Network pharmacology-based prediction of the active ingredients and potential targets of Mahuang Fuzi Xixin decoction for application to allergic rhinitis," Journal of Ethnopharmacology, vol. 176, pp. 402-412, 2015.

[105] Y. Li, C. Han, J. Wang et al., "Investigation into the mechanism of Eucommia ulmoides Oliv. based on a systems pharmacology approach," Journal of Ethnopharmacology, vol. 151, no. 1, pp. 452-460, 2014.

[106] J. Zhu, X. Yi, Y. Zhang, Z. Pan, L. Zhong, and P. Huang, "Systems pharmacology-based approach to comparatively study the independent and synergistic mechanisms of danhong injection and naoxintong capsule in ischemic stroke treatment," Evidence-Based Complementary and Alternative Medicine, vol. 2019, Article ID 1056708, 17 pages, 2019.

[107] J. Zhong, Z. Liu, X. Zhou, and J. Xu, "Synergic anti-pruritus mechanisms of action for the radix sophorae flavescentis and fructus Cnidii herbal pair," Molecules, vol. 22, no. 9, p. 1465, 2017.

[108] D. Y. Cho, Y. A. Kim, and T. M. Przytycka, "Chapter 5: network biology approach to complex diseases," PLoS Computational Biology, vol. 8, no. 12, Article ID e1002820, 2012.

[109] H. Jeong, S. P. Mason, A. L. Barabasi, and Z. N. Oltvai, "Lethality and centrality in protein networks," Nature, vol. 411, no. 6833, pp. 41-42, 2001.
[110] M. Yamashita and E. Passegué, "TNF- $\alpha$ coordinates hematopoietic stem cell survival and myeloid regeneration," Cell Stem Cell, vol. 25, no. 3, pp. 357-372, 2019.

[111] S. J. Stein and A. S. Baldwin, "Deletion of the NF- $\kappa$ B subunit p65/RelA in the hematopoietic compartment leads to defects in hematopoietic stem cell function," Blood, vol. 121, no. 25, pp. 5015-5024, 2013.

[112] C. Ruiz-Herguido, J. Guiu, T. D'Altri et al., "Hematopoietic stem cell development requires transient $\mathrm{Wnt} / \beta$-catenin activity," The Journal of Experimental Medicine, vol. 209, no. 8, pp. 1457-1468, 2012.

[113] T. C. Luis, B. A. Naber, P. P. Roozen et al., "Canonical wnt signaling regulates hematopoiesis in a dosage-dependent fashion," Cell Stem Cell, vol. 9, no. 4, pp. 345-356, 2011.

[114] M. M. Juntilla, V. D. Patil, M. Calamito, R. P. Joshi, M. J. Birnbaum, and G. A. Koretzky, "AKT1 and AKT2 maintain hematopoietic stem cell function by regulating reactive oxygen species," Blood, vol. 115, no. 20, pp. 40304038, 2010.

[115] C. K. Huang, J. Luo, S. O. Lee, and C. Chang, "Concise review: androgen receptor differential roles in stem/progenitor cells including prostate, embryonic, stromal, and hematopoietic lineages," Stem Cells, vol. 32, no. 9, pp. 2299-2308, 2014.

[116] M. Tesio, Y. Tang, K. Mudder et al., "Hematopoietic stem cell quiescence and function are controlled by the CYLDTRAF2-p38MAPK pathway," The Journal of Experimental Medicine, vol. 212, no. 4, pp. 525-538, 2015.

[117] A. Baudet, C. Karlsson, M. Safaee Talkhoncheh, R. Galeev, M. Magnusson, and J. Larsson, "RNAi screen identifies MAPK14 as a druggable suppressor of human hematopoietic stem cell expansion," Blood, vol. 119, no. 26, pp. 6255-6258, 2012.

[118] Y. Wang, J. Kellner, L. Liu, and D. Zhou, "Inhibition of p38 mitogen-activated protein kinase promotes ex vivo hematopoietic stem cell expansion," Stem Cells and Development, vol. 20, no. 7, pp. 1143-1152, 2011.

[119] K. Ito, A. Hirao, F. Arai et al., "Reactive oxygen species act through p38 MAPK to limit the lifespan of hematopoietic stem cells," Nature Medicine, vol. 12, no. 4, pp. 446-451, 2006.

[120] D. Nakada, H. Oguro, B. P. Levi et al., "Oestrogen increases haematopoietic stem-cell self-renewal in females and during pregnancy," Nature, vol. 505, no. 7484, pp. 555-558, 2014.

[121] H. R. Kim, J. H. Lee, H. R. Heo et al., "Improved hematopoietic differentiation of human pluripotent stem cells via estrogen receptor signaling pathway," Cell \& Bioscience, vol. 6, no. 1, p. 50, 2016.

[122] A. Sanchez-Aguilera, L. Arranz, D. Martin-Perez et al., "Estrogen signaling selectively induces apoptosis of hematopoietic progenitors and myeloid neoplasms without harming steady-state hematopoiesis," Cell Stem Cell, vol. 15, no. 6, pp. 791-804, 2014.

[123] C. R. Geest and P. J. Coffer, "MAPK signaling pathways in the regulation of hematopoiesis," Journal of Leukocyte Biology, vol. 86, no. 2, pp. 237-250, 2009.

[124] S. M. Jacobs-Helber and S. T. Sawyer, "Jun N-terminal kinase promotes proliferation of immature erythroid cells and erythropoietin-dependent cell lines," Blood, vol. 104, no. 3, pp. 696-703, 2004

[125] S. M. Jacobs-Helber, A. Wickrema, M. J. Birrer, and S. T. Sawyer, "AP1 regulation of proliferation and initiation of apoptosis in erythropoietin-dependent erythroid cells," 
Molecular and Cellular Biology, vol. 18, no. 7, pp. 3699-3707, 1998.

[126] Y. Nagata, N. Takahashi, R. J. Davis, and K. Todokoro, "Activation of p38 MAP kinase and JNK but not ERK is required for erythropoietin-induced erythroid differentiation," Blood, vol. 92, no. 6, pp. 1859-1869, 1998.

[127] P. L. Doan, H. A. Himburg, K. Helms et al., "Epidermal growth factor regulates hematopoietic regeneration after radiation injury," Nature Medicine, vol. 19, no. 3, pp. 295304, 2013.

[128] L. Laterveer, I. J. Lindley, M. S. Hamilton, R. Willemze, and W. E. Fibbe, "Interleukin- 8 induces rapid mobilization of hematopoietic stem cells with radioprotective capacity and long-term myelolymphoid repopulating ability," Blood, vol. 85, no. 8, pp. 2269-2275, 1995.

[129] J. Chapman and Y. Zhang, Histology, Hematopoiesis, StatPearls Publishing, Treasure Island, FL, USA, 2019.

[130] H. M. Lazarus and A. H. Schmaier, Concise Guide to Hematology, Springer, Berlin, Germany, 2012.

[131] M. T. Baldridge, K. Y. King, and M. A. Goodell, "Inflammatory signals regulate hematopoietic stem cells," Trends in Immunology, vol. 32, no. 2, pp. 57-65, 2011.

[132] U. Blank, G. Karlsson, and S. Karlsson, "Signaling pathways governing stem-cell fate," Blood, vol. 111, no. 2, pp. 492-503, 2008.

[133] K. Chotinantakul and W. Leeanansaksiri, "Hematopoietic stem cell development, niches, and signaling pathways," Bone Marrow Research, vol. 2012, Article ID 270425, 16 pages, 2012.

[134] A. D. Kim, D. L. Stachura, and D. Traver, "Cell signaling pathways involved in hematopoietic stem cell specification," Experimental Cell Research, vol. 329, no. 2, pp. 227-233, 2014.

[135] A. Kumar, S. S. D'Souza, and A. S. Thakur, "Understanding the journey of human hematopoietic stem cell development," Stem Cells International, vol. 2019, Article ID 2141475, 13 pages, 2019.

[136] C. S. Martin, A. Moriyama, and L. I. Zon, "Hematopoietic stem cells, hematopoiesis and disease: lessons from the zebrafish model," Genome Medicine, vol. 3, no. 12, p. 83, 2011.

[137] E. Passegue, C. H. Jamieson, L. E. Ailles, and I. L. Weissman, "Normal and leukemic hematopoiesis: are leukemias a stem cell disorder or a reacquisition of stem cell characteristics?," Proceedings of the National Academy of Sciences, vol. 100, no. 1, pp. 11842-11849, 2003.

[138] Z. L. Whichard, C. A. Sarkar, M. Kimmel, and S. J. Corey, "Hematopoiesis and its disorders: a systems biology approach," Blood, vol. 115, no. 12, pp. 2339-2347, 2010.

[139] S. Hemmati, T. Sinclair, M. Tong et al., "PI3 kinase alpha and delta promote hematopoietic stem cell activation," JCI Insight, vol. 5, no. 13, 2019.

[140] M. M. Nakagawa, H. Chen, and C. V. Rathinam, "Constitutive activation of NF- $\kappa$ B pathway in hematopoietic stem cells causes loss of quiescence and deregulated transcription factor networks," Frontiers in Cell and Developmental Biology, vol. 6, p. 143, 2019.

[141] V. Menon and S. Ghaffari, "Transcription factors FOXO in the regulation of homeostatic hematopoiesis," Current Opinion in Hematology, vol. 25, no. 4, pp. 290-298, 2018.

[142] M. Vukovic, C. Sepulveda, C. Subramani et al., "Adult hematopoietic stem cells lacking Hif- $1 \alpha$ self-renew normally," Blood, vol. 127, no. 23, pp. 2841-2846, 2016.
[143] R. K. O’Donnell, B. Falcon, J. Hanson et al., "VEGF-A/ VEGFR inhibition restores hematopoietic homeostasis in the bone marrow and attenuates tumor growth," Cancer Research, vol. 76, no. 3, pp. 517-524, 2016.

[144] C. E. Forristal, B. Nowlan, R. N. Jacobsen et al., "HIF- $1 \alpha$ is required for hematopoietic stem cell mobilization and 4prolyl hydroxylase inhibitors enhance mobilization by stabilizing HIF-1 $\alpha$," Leukemia, vol. 29, no. 6, pp. 1366-1378, 2015.

[145] G. Chan, S. Gu, and B. G. Neel, "Erk1 and Erk2 are required for maintenance of hematopoietic stem cells and adult hematopoiesis," Blood, vol. 121, no. 18, pp. 3594-3598, 2013.

[146] J. A. Magee, T. Ikenoue, D. Nakada, J. Y. Lee, K. L. Guan, and S. J. Morrison, "Temporal changes in PTEN and mTORC2 regulation of hematopoietic stem cell self-renewal and leukemia suppression," Cell Stem Cell, vol. 11, no. 3, pp. 415-428, 2012.

[147] C. Zhao, Y. Xiu, J. Ashton et al., "Noncanonical NF- $\kappa$ B signaling regulates hematopoietic stem cell self-renewal and microenvironment interactions," Stem Cells, vol. 30, no. 4, pp. 709-718, 2012.

[148] R. Polak and M. Buitenhuis, "The PI3K/PKB signaling module as key regulator of hematopoiesis: implications for therapeutic strategies in leukemia," Blood, vol. 119, no. 4, pp. 911-923, 2012.

[149] K. Takubo, N. Goda, W. Yamada et al., "Regulation of the HIF- $1 \alpha$ level is essential for hematopoietic stem cells," Cell Stem Cell, vol. 7, no. 3, pp. 391-402, 2010.

[150] M. G. Kharas, R. Okabe, J. J. Ganis et al., "Constitutively active AKT depletes hematopoietic stem cells and induces leukemia in mice," Blood, vol. 115, no. 7, pp. 1406-1415, 2010.

[151] M. Buitenhuis and P. J. Coffer, "The role of the PI3K-PKB signaling module in regulation of hematopoiesis," Cell Cycle, vol. 8, no. 4, pp. 560-566, 2009.

[152] K. Miyamoto, T. Miyamoto, R. Kato, A. Yoshimura, N. Motoyama, and T. Suda, "FoxO3a regulates hematopoietic homeostasis through a negative feedback pathway in conditions of stress or aging," Blood, vol. 112, no. 12, pp. 4485-4493, 2008.

[153] Z. Tothova and D. G. Gilliland, "FoxO transcription factors and stem cell homeostasis: insights from the hematopoietic system," Cell Stem Cell, vol. 1, no. 2, pp. 140-152, 2007.

[154] K. Miyamoto, K. Y. Araki, K. Naka et al., "FoxO3a is essential for maintenance of the hematopoietic stem cell pool," Cell Stem Cell, vol. 1, no. 1, pp. 101-112, 2007.

[155] L. Zhou, J. Opalinska, and A. Verma, "p38 MAP kinase regulates stem cell apoptosis in human hematopoietic failure," Cell Cycle, vol. 6, no. 5, pp. 534-537, 2007.

[156] Z. Tothova, R. Kollipara, B. J. Huntly et al., "FoxOs are critical mediators of hematopoietic stem cell resistance to physiologic oxidative stress," Cell, vol. 128, no. 2, pp. 325-339, 2007.

[157] V. Bottero, S. Withoff, and I. M. Verma, "NF- $\kappa$ B and the regulation of hematopoiesis," Cell Death \& Differentiation, vol. 13, no. 5, pp. 785-797, 2006.

[158] H. P. Gerber and N. Ferrara, "The role of VEGF in normal and neoplastic hematopoiesis," Journal of Molecular Medicine, vol. 81, no. 1, pp. 20-31, 2003.

[159] H. P. Gerber, A. K. Malik, G. P. Solar et al., "VEGF regulates haematopoietic stem cell survival by an internal autocrine loop mechanism," Nature, vol. 417, no. 6892, pp. 954-958, 2002. 
[160] V. H. Haase, "Regulation of erythropoiesis by hypoxia-inducible factors," Blood Reviews, vol. 27, no. 1, pp. 41-53, 2013.

[161] M. L. Capitano, "Toll-like receptor signaling in hematopoietic stem and progenitor cells," Current Opinion in Hematology, vol. 26, no. 4, pp. 207-213, 2019.

[162] D. A. Monlish, S. T. Bhatt, and L. G. Schuettpelz, "The role of toll-like receptors in hematopoietic malignancies," Frontiers in Immunology, vol. 7, p. 390, 2016.

[163] J. Cannova, S. J. P. Breslin, and J. Zhang, "Toll-like receptor signaling in hematopoietic homeostasis and the pathogenesis of hematologic diseases," Frontiers of Medicine, vol. 9, no. 3, pp. 288-303, 2015.

[164] Y. Zhang, A. Harada, H. Bluethmann et al., "Tumor necrosis factor (TNF) is a physiologic regulator of hematopoietic progenitor cells: increase of early hematopoietic progenitor cells in TNF receptor p55-deficient mice in vivo and potent inhibition of progenitor cell proliferation by TNF alpha in vitro," Blood, vol. 86, no. 8, pp. 2930-2937, 1995.

[165] S. E. Jacobsen, F. W. Jacobsen, C. Fahlman, and L. S. Rusten, "TNF- $\alpha$, the great imitator: role of p55 and p75 TNF receptors in hematopoiesis," Stem Cells, vol. 12, no. 1, pp. 111-126, 1994.

[166] V. Pant, A. Quintas-Cardama, and G. Lozano, "The p53 pathway in hematopoiesis: lessons from mouse models, implications for humans," Blood, vol. 120, no. 26, pp. 5118-5127, 2012.

[167] H. A. Abbas, V. Pant, and G. Lozano, "The ups and downs of p53 regulation in hematopoietic stem cells," Cell Cycle, vol. 10, no. 19, pp. 3257-3262, 2011.

[168] T. Asai, Y. Liu, N. Bae, and S. D. Nimer, "The p53 tumor suppressor protein regulates hematopoietic stem cell fate," Journal of Cellular Physiology, vol. 226, no. 9, pp. 2215-2221, 2011.

[169] T. Bondar and R. Medzhitov, "p53-mediated hematopoietic stem and progenitor cell competition," Cell Stem Cell, vol. 6, no. 4, pp. 309-322, 2010.

[170] Y. Liu, S. E. Elf, T. Asai et al., "The p53 tumor suppressor protein is a critical regulator of hematopoietic stem cell behavior," Cell Cycle, vol. 8, no. 19, pp. 3120-3124, 2009.

[171] Y. Liu, S. E. Elf, Y. Miyata et al., "p53 regulates hematopoietic stem cell quiescence," Cell Stem Cell, vol. 4, no. 1, pp. 37-48, 2009.

[172] M. J. McGeachy, D. J. Cua, and S. L. Gaffen, "The IL-17 family of cytokines in health and disease," Immunity, vol. 50, no. 4, pp. 892-906, 2019.

[173] S. Mojsilovic, A. Jaukovic, J. F. Santibanez, and D. Bugarski, "Interleukin-17 and its implication in the regulation of differentiation and function of hematopoietic and mesenchymal stem cells," Mediators of Inflammation, vol. 2015, Article ID 470458, 11 pages, 2015.

[174] A. Krstic, S. Mojsilovic, G. Jovcic, and D. Bugarski, "The potential of interleukin-17 to mediate hematopoietic response," Immunologic Research, vol. 52, no. 1-2, pp. 34-41, 2012.

[175] W. Tan, W. Huang, X. Gu, Q. Zhong, B. Liu, and P. Schwarzenberger, "IL-17F/IL-17R interaction stimulates granulopoiesis in mice," Experimental Hematology, vol. 36, no. 11, pp. 1417-1427, 2008.

[176] L. A. Tesmer, S. K. Lundy, S. Sarkar, and D. A. Fox, "Th17 cells in human disease," Immunological Reviews, vol. 223, pp. 87-113, 2008.

[177] G. Jovcic, D. Bugarski, A. Krstic et al., "The effect of interleukin-17 on hematopoietic cells and cytokine release in mouse spleen," Physiological Research, vol. 56, no. 3, pp. 331-339, 2007.

[178] W. Tan, W. Huang, Q. Zhong, and P. Schwarzenberger, "IL17 receptor knockout mice have enhanced myelotoxicity and impaired hemopoietic recovery following gamma irradiation," The Journal of Immunology, vol. 176, no. 10, pp. 6186-6193, 2006.

[179] G. Jovcic, D. Bugarski, M. Petakov et al., "In vivo effects of interleukin-17 on haematopoietic cells and cytokine release in normal mice," Cell Proliferation, vol. 37, no. 6, pp. 401-412, 2004.

[180] G. Jovcic, D. Bugarski, M. Petakov, J. Stankovic, N. Stojanovic, and P. Milenkovic, "Effect of IL-17 on in vitro hematopoietic progenitor cells growth and cytokine release in normal and post-irradiated murine bone marrow," Growth Factors, vol. 19, no. 1, pp. 61-71, 2001.

[181] P. Schwarzenberger, V. La Russa, A. Miller et al., "IL-17 stimulates granulopoiesis in mice: use of an alternate, novel gene therapy-derived method for in vivo evaluation of cytokines," Journal of Immunology, vol. 161, no. 11, pp. 6383-6389, 1998.

[182] F. Fossiez, O. Djossou, P. Chomarat et al., "T cell interleukin17 induces stromal cells to produce proinflammatory and hematopoietic cytokines," The Journal of Experimental Medicine, vol. 183, no. 6, pp. 2593-2603, 1996.

[183] J. Montojo, K. Zuberi, H. Rodriguez, G. D. Bader, and Q. Morris, "GeneMANIA: fast gene network construction and function prediction for cytoscape," F1000Research, vol. 3, p. 153, 2014.

[184] X. Zhou, S. W. Seto, D. Chang et al., "Synergistic effects of Chinese herbal medicine: a comprehensive review of methodology and current research," Frontiers in Pharmacology, vol. 7, p. 201, 2016.

[185] C. G. Son, S. H. Han, J. H. Cho et al., "Induction of hemopoiesis by saenghyuldan, a mixture of ginseng radix, paeoniae radix alba, and hominis placenta extracts," Acta Pharmacologica Sinica, vol. 24, no. 2, pp. 120-126, 2003.

[186] K. J. Park, B. C. Lee, J. S. Lee, and M. H. Cho, "Angelica gigas Nakai extract ameliorates the effects of cyclophosphamide on immunological and hematopoietic dysfunction in mice," Journal of Medicinal Plants Research, vol. 8, no. 17, pp. 657-663, 2014.

[187] L. Fraile, E. Crisci, L. Cordoba, M. A. Navarro, J. Osada, and M. Montoya, "Immunomodulatory properties of beta-sitosterol in pig immune responses," International Immunopharmacology, vol. 13, no. 3, pp. 316-321, 2012.

[188] S. Swarnalatha and A. Puratchikody, "Cytokine mediated immunomodulatory properties of kaempferol-5-O- $\beta$-Dglucopyranoside from methanol extract of aerial parts of Indigofera aspala-thoides Vahl ex DC," International Journal of Research in Pharmaceutical Sciences, vol. 5, no. 1, pp. 73-78, 2014.

[189] X. Zheng, W.-w. Hou, P.-f. Duan et al., "Immunomodulatory effect of prepared radix rehmanniae extract in vitro," Chinese Pharmaceutical Journal, vol. 47, no. 24, pp. 1995-2000, 2012.

[190] L. Alappat, M. Valerio, and A. B. Awad, "Effect of vitamin D and beta-sitosterol on immune function of macrophages," International Immunopharmacology, vol. 10, no. 11, pp. 1390-1396, 2010.

[191] P. J. Bouic, S. Etsebeth, R. W. Liebenberg, C. F. Albrecht, K. Pegel, and P. P. Van Jaarsveld, "Beta-sitosterol and betasitosterol glucoside stimulate human peripheral blood lymphocyte proliferation: implications for their use as an immunomodulatory vitamin combination," International 
Journal of Immunopharmacology, vol. 18, no. 12, pp. 693700, 1996.

[192] F. Takano, T. Tanaka, J. Aoi, N. Yahagi, and S. Fushiya, "Protective effect of $(+)$-catechin against 5-fluorouracil-induced myelosuppression in mice," Toxicology, vol. 201, no. 1-3, pp. 133-142, 2004.

[193] Y. Zhu, L. Wang, Z. Yang et al., "Hematopoietic effects of paeoniflorin and albiflorin on radiotherapy-induced myelosuppression mice," Evidence-Based Complementary and Alternative Medicine, vol. 2016, Article ID 5789381, 8 pages, 2016.

[194] L. L. Liu, Z. C. Ma, Y. G. Wang et al., "Effects of Siwu decoction on bone marrow protein expression of blood deficiency mice induced by cyclophosphamide," Zhongguo Zhong Yao Za Zhi, vol. 31, no. 14, pp. 1172-1175, 2006.

[195] Q. D. Liang, Y. Gao, H. L. Tan et al., "Effects of four Si-WuTang's constituents and their combination on irradiated mice," Biological \& Pharmaceutical Bulletin, vol. 29, no. 7, pp. 1378-1382, 2006.

[196] P. Guo, Z. C. Ma, Y. F. Li, Q. D. Liang, J. F. Wang, and S. Q. Wang, "Effects of siwu tang on protein expression of bone marrow of blood deficiency mice induced by irradiation," Zhongguo Zhong Yao Za Zhi, vol. 29, no. 9, pp. 893896, 2004.

[197] S. E. Lee, H. Oh, J. A. Yang et al., "Radioprotective effects of two traditional Chinese medicine prescriptions: si-Wu-tang and Si-jun-zi-tang," The American Journal of Chinese Medicine, vol. 27, no. 3-4, pp. 387-396, 1999.

[198] W. Tan, C. S. Song, H. L. Tan et al., "Hematopoietic effect of Siwu decoction in the mice with blood deficiency induced by compound method of bleeding, starved feeding and exhausting," Zhongguo Zhong Yao Za Zhi, vol. 30, no. 12, pp. 926-929, 2005.

[199] Z. C. Ma, Y. Gao, H. L. Tang, and S. Q. Wang, "The effects of $\mathrm{Si}$-Wu-Tang on serum protein of blood deficient mice induced by radiation," Zhongguo Zhong Yao Za Zhi, vol. 28, no. 11, pp. 1050-1053, 2003.

[200] P. Guo and S.-q. Wang, "Effect of Siwu decoction and its active monomers on NF- $\kappa \mathrm{B}$ and TGF- $\beta \_1$ gene expressions in the bone marrow cells of blood deficiency pattern mice," Journal of Shandong University of Traditional Chinese Medicine, vol. 4, 2015.

[201] H. Tan, Z. Ma, Y. Gao, Y. Liu, C. Xiao, and X. Lu, "Effects of Siwu Tang on CD34 antigen expression in one marrow of mice with blood deficiency," Traditional Chinese Drug Research \& Clinical Pharmacology, vol. 13, pp. 11-13, 2002.

[202] Y. Tian, Y. Xiang, G. Wan et al., "Effects and mechanisms of Bazhen decoction, Siwu decoction, and Sijunzi decoction on 5 -fluorouracil-induced anemia in mice," Journal of Traditional Chinese Medicine, vol. 36, no. 4, pp. 486-495, 2016.

[203] G. Ping and W. Shengqi, "The study on blood enriching function of Siwu decoction and its active monomers on blood-deficiency mice," Pharmacology and Clinics of Chinese Materia Medica, vol. 6, p. 3, 2012.

[204] D.-H. Yu, J. Kwon, C.-H. Oh, and J.-S. Eun, "Effects of SaMul-Tang on immunocytes of L1210 cells-transplanted or antitumor drugs-administered mice," Korean Journal of Pharmacognosy, vol. 29, no. 2, pp. 110-119, 1998. 